\title{
Patient knowledge, perceptions, and acceptance of generic medicines: a comprehensive review of the current literature
}

This article was published in the following Dove Press journal:

Patient Intelligence

3 April 2014

Number of times this article has been viewed

\author{
Alian A Alrasheedy' \\ Mohamed Azmi Hassali' \\ Kay Stewart ${ }^{2}$ \\ David CM Kong ${ }^{2}$ \\ Hisham Aljadhey ${ }^{3}$ \\ Mohamed Izham Mohamed \\ Ibrahim ${ }^{4}$ \\ Saleh Karamah Al-Tamimi' \\ 'Discipline of Social and \\ Administrative Pharmacy, School \\ of Pharmaceutical Sciences, \\ Universiti Sains Malaysia, Penang, \\ Malaysia; ' ${ }^{2}$ aculty of Pharmacy \\ and Pharmaceutical Sciences, \\ Monash University, Melbourne, \\ VIC, Australia; ${ }^{3}$ Medication Safety \\ Research Chair, Clinical Pharmacy \\ Department, College of Pharmacy, \\ King Saud University, Riyadh, Saudi \\ Arabia; ${ }^{4}$ College of Pharmacy, Qatar \\ University, Doha, Qatar
}

Correspondence: Alian A Alrasheedy Discipline of Social and Administrative Pharmacy, School of Pharmaceutical Sciences, Universiti Sains Malaysia,

I 800 Penang, Malaysia

Email alian-a@hotmail.com
Background: Generic medicines have the same quality, safety, and efficacy as their counterpart original brand medicines. Generic medicines provide the same therapeutic outcomes but at a much cheaper cost, so are promoted in many countries to contain pharmaceutical expenditure and sustain the health care system. Thus, the perspective of patients and medicine consumers as end users of these medicines is an important factor to enhance the use and utilization of generic medicines. The objective of this paper is to review patients' and consumers' knowledge, perceptions, acceptance, and views of generic medicines in the current literature.

Methods: An extensive literature search was performed in several databases, namely Scopus, PubMed, ISI Web of Knowledge, Proquest, and the Wiley online library, to identify relevant studies published in the English literature for the period 1990-2013.

Results: A total of 53 studies were included in the review, comprising 24 studies from Europe, ten from North America, six from Asia, five from Australia and New Zealand, five from the Middle East, one from Africa, one from Latin America, and one from the Caribbean region. A large body of literature has reported misconceptions and negative perceptions about generic medicines on the part of patients and medicine consumers. Moreover, although it is reported in almost all countries, the percentage of consumers who had such misconceptions varied from one country to another. However, in many countries, there was a meaningful percentage of patients who had negative perceptions and misconceptions about generic medicines. Moreover, such misconceptions and negative perceptions were reported as major obstacles to the use and acceptance of generic medicines among patients. Further, studies that focused on specific populations (eg, patients with epilepsy, psychosis, or renal disease) reported a more negative perception and more resistance to the use of generic medicines. The type of medical condition and its level of seriousness or severity, recommendations by health care professionals, price difference (ie, cost saving), previous experience of generic medicines, and knowledge/information about generic medicines were considered to be important factors that affect a patient's decision to use a generic medicine or a brand medicine.

Conclusion: The results from this literature search show that patients and medicine consumers tend to prefer original brand medicines over generic medicines. Further, in many countries, there is still a considerable proportion of patients and consumers who lack adequate knowledge or have insufficient information about generic medicines. Thus, there is a need for educational interventions and activities to educate patients about generic medicines. It is also evident in the literature that health care professionals (physicians and pharmacists) play a key role in the promotion of generic medicines and in patients' acceptance of generic medicines and generic substitution. Hence, health care professionals need to play a more active role by educating patients and recommending generic medicines to their patients.

Keywords: patients, generic substitution, perceptions, policy 


\section{Introduction}

Generic medicine can be defined in different ways in different countries. ${ }^{1}$ However, the term is commonly understood, as defined by the World Health Organization, to mean "a pharmaceutical product, usually intended to be interchangeable with an innovator product that is manufactured without a license from the innovator company and marketed after the expiry date of the patent or other exclusive rights". ${ }^{2}$ Generic medicines are required to have the same active substance, strength, pharmaceutical form, and route of administration as their brand counterparts, but can be different in some aspects, such as inactive ingredients, color, and shape. ${ }^{3}$ Before registration, similar to all medicines including original brand products, a generic medicine must pass through a rigorous registration process and stringent requirements to ensure its quality, safety, and efficacy, and that it meets all the required standards. ${ }^{3,4}$ Further, the concept of bioequivalence is an essential requirement for the approval of generic medicines. ${ }^{5}$ Bioequivalence is investigated to demonstrate clinical equivalence of the generic medicine with its counterpart original brand, and hence repeating the preclinical and clinical testing performed on the original brand is not required. ${ }^{1}$

Generic medicines are much cheaper than their equivalent brand medicines ${ }^{6-9}$ and are available as standard therapy for many acute and chronic diseases. ${ }^{8,10}$ Thus, wide use of generic medicines would not only decrease medicine expenditure but also be essential for the sustainability of the health care system. ${ }^{11}$ Therefore, in recent years, to confront the escalation of health care expenditure in general, and pharmaceutical expenditure in particular, many governments and third-party payers have encouraged the use of generic medicines as an integral part of the health care system by instigating and implementing various policies, initiatives, and strategies. ${ }^{12-17}$ Amidst them all, the acceptance of generic medicines by patients is an important issue and an essential factor given that patients are the end users of these pharmaceutical products. ${ }^{18}$ In fact, correct understanding, knowledge, and positive perceptions are prerequisite to acceptance of generic medicines by patients. ${ }^{18}$ Thus, the aim of this review was to determine patients' and medicine consumers' knowledge, perceptions, acceptance, and attitudes towards generic medicines and generic substitution and to explore the factors that influence their acceptance of generic medicines.

\section{Methodology}

An extensive literature search was performed to identify published studies related to perceptions, views, opinions, understanding, knowledge, and acceptance of generic medicines. Studies that employed either qualitative or quantitative methods or both were included in the study. The search strategy and identification of studies was performed according to the PRISMA (Preferred Reporting Items for Systematic Reviews and Meta-Analyses) statement. ${ }^{19}$ An extensive literature search using several electronic databases, namely Scopus, PubMed, ISI Web of Knowledge, Proquest, and the Wiley online library was performed. The bibliographies of the retrieved articles were also reviewed for further potential studies. The search strategy involved using Boolean operators for combinations of several keywords to identify the relevant articles. To make the search broad and comprehensive and to include as many relevant articles as possible, the stem word "generic" was used to represent the keywords, ie, generic medicine(s), generic drug(s), generic medication(s), generics, and generic substitution. For patients, the following keywords were used: patient(s), consumer(s), customer(s), people, lay. For all five databases, the search was as follows: generic AND [patient(s) OR consumer(s), OR customer(s) OR people OR lay]. The search was restricted to article titles. In order to capture studies that used only the generic term in the title, we searched the databases (Scopus and PubMed) for such studies using this research formula in Scopus: (generic medicines OR generic medications) AND NOT [patient(s) OR consumer(s), OR customer(s) OR people OR lay OR pharmacist(s) OR physician(s)]; and this formula in PubMed: (generics OR generic medicines OR generic medications) AND NOT (patients OR consumers, OR customers OR people OR lay OR pharmacists OR physicians). The research was restricted to journal articles, human studies, and publication in the period 1990-2013. Moreover, in this review, only studies that investigated patients/consumers' knowledge, perceptions, attitude, views, and acceptance of generic medicines were included. Other studies not related to the topic or articles that were not really assessing patient/ consumer perceptions towards generic medicines, but rather largely looking at the clinical effectiveness of generic medicines in patient populations were excluded. Only articles published in the English language were included. To determine whether or not the reports met the required criteria (ie, related to the topic and published in English), the lists of titles and abstracts from the searches were examined by two reviewers independently, and where doubt remained, the whole paper was examined. In addition to systematic search of the databases, the authors also searched their own EndNote libraries which contained studies related to patients and generic medicines.

\section{Results}

The search process resulted in 1,441 titles and abstracts. After removing duplicates, 669 abstracts and titles were screened. 
Of these, 594 were excluded because they were not totally related to the topic or did not investigate the perceptions, views, or knowledge of patients towards generic medicines. The remaining papers $(n=75)$ were full-text and assessed for eligibility for inclusion in the study. Of these, 22 were excluded because they were not actually related to patients' knowledge, perceptions, attitudes, and acceptance of generic medicines. As a result, 53 studies were included in the final review. The PRISMA diagram for this review is shown in Figure 1. Because the studies were conducted in different countries, they are presented in seven groups, namely studies from North America $(\mathrm{n}=10)$, Australia and New Zealand $(n=5)$, Asia $(n=6)$, Europe $(n=24)$, the Middle East $(n=5)$, and Latin America, Africa, and Caribbean region $(n=3)$. When there was more than one study from the same country, the studies were arranged in chronological order.

\section{Studies from the USA and Canada}

There were ten studies identified from the USA and Canada. A summary of the characteristics of these studies is presented in Table 1. Ganther and Kreling ${ }^{20}$ conducted a survey in Wisconsin to evaluate patients' perception of the risks of generic medicines prescribed for the treatment of different medical conditions (heart problems, hypertension, "strep throat", pain, and cough) and to determine the relationship between risk perception and the required amount of cost saving that would make the patients switch to the generic equivalent. The study findings showed that the perception of generic medicines as being riskier than brand medicines varied widely, from $14.2 \%$ for coughs to $53.8 \%$ for heart problems. This study also showed that the higher the patients' perceived risk of the medical condition, the greater/larger the cost saving required to switch to a generic version. In this study, only $2.6 \%$ of participants would not accept generic medicines for a cough regardless of the price or cost savings, while a higher percentage $(27.2 \%)$ were not willing to accept generic medicines for heart problems. The authors concluded that patients' perception of risk varies for different medical conditions. Accordingly, the required cost saving to switch to generic medicines also varies according

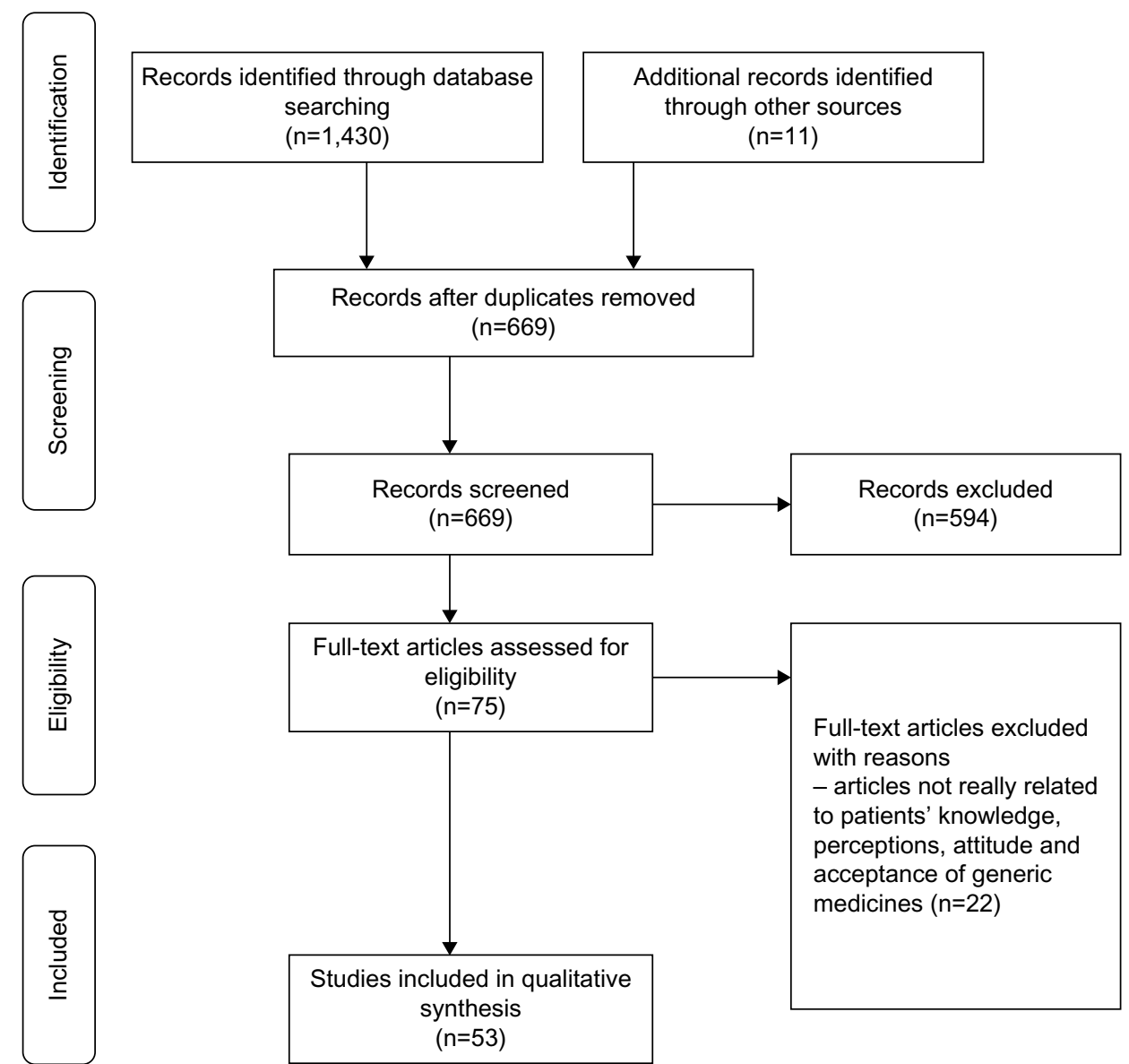

Figure I The PRISMA diagram.

Note: The template of flow diagram is adapted from (C) 2009 Moher et al. This is an open-access article distributed under the terms of the Creative Commons Attribution License, which permits unrestricted use, distribution, and reproduction in any medium, provided the original author and source are credited. ${ }^{19}$

Abbreviation: PRISMA, Preferred Reporting Items for Systematic Reviews and Meta-Analyses. 
Table I Summary of the studies included in the review investigating patients' perceptions and acceptance of generic medicines in North America (the USA and Canada)

\begin{tabular}{|c|c|c|c|c|}
\hline Study & Country & Methods & Population and sample size & Limitations \\
\hline $\begin{array}{l}\text { Ganther and } \\
\text { Kreling }^{20}\end{array}$ & $\begin{array}{l}\text { Wisconsin, } \\
\text { USA }\end{array}$ & $\begin{array}{l}\text { A cross-sectional } \\
\text { mail survey }\end{array}$ & $\begin{array}{l}\text { A total of } 355 \text { usable } \\
\text { questionnaires were included in } \\
\text { the study (response rate } 71.4 \% \text { ) } \\
\text { General patients and consumers }\end{array}$ & $\begin{array}{l}\text { The study was conducted in a small region in one } \\
\text { state, so generalization is limited } \\
\text { The study examined the overall risk of generic } \\
\text { medicine utilization and the reported behavior; } \\
\text { however, specific types of risk and actual behavior } \\
\text { were not examined }\end{array}$ \\
\hline $\begin{array}{l}\text { Sansgiry } \\
\text { et } \mathrm{al}^{21}\end{array}$ & $\begin{array}{l}\text { Houston, } \\
\text { Texas, USA }\end{array}$ & $\begin{array}{l}\text { Self-administered } \\
\text { questionnaire-based } \\
\text { study }\end{array}$ & $\begin{array}{l}505 \text { consumers, (response } \\
\text { rate } 60.5 \% \text { ) } \\
\text { General population }\end{array}$ & $\begin{array}{l}\text { The study was done in ten pharmacies in Houston, so } \\
\text { the findings might not be generalizable to other areas } \\
\text { General issues pertaining to respondent bias } \\
\text { and study design } \\
\text { The study sample was relatively homogenous }\end{array}$ \\
\hline $\begin{array}{l}\text { losifescu } \\
\text { et } \mathrm{al}^{22}\end{array}$ & $\begin{array}{l}\text { New York, } \\
\text { USA }\end{array}$ & $\begin{array}{l}\text { Interviewer- } \\
\text { administered } \\
\text { questionnaire-based } \\
\text { study }\end{array}$ & $\begin{array}{l}315 \text { participants (recruitment } \\
\text { rate } 43 \% \text { ) } \\
\text { Elderly adults ( } \geq 65 \text { years) who } \\
\text { were enrolled in Medicare (the } \\
\text { federal health insurance program } \\
\text { for elderly and disabled adults in } \\
\text { the USA) }\end{array}$ & $\begin{array}{l}\text { Most study participants had government insurance } \\
\text { (ie, Medicaid) and were perhaps less sensitive to } \\
\text { medicine costs than other adults with low income } \\
\text { who need to pay more for their medicines } \\
\text { The study was conducted in a single institution with a } \\
\text { low rate of participation } \\
\text { Actual use of generic medicines was not measured }\end{array}$ \\
\hline $\begin{array}{l}\text { Shrank } \\
\text { et } \mathrm{al}^{23}\end{array}$ & $\begin{array}{l}\text { USA national } \\
\text { survey }\end{array}$ & Mail survey & $\begin{array}{l}\text { I,047 usable questionnaires } \\
\text { (response rate } 48 \% \text { ) } \\
\text { Commercially insured patients }\end{array}$ & $\begin{array}{l}\text { The study focused on and included only commercially } \\
\text { insured patients; this limits the generalization of } \\
\text { findings to uninsured patients and government (state } \\
\text { or federal) insured patients }\end{array}$ \\
\hline $\begin{array}{l}\text { Shrank } \\
\text { et } \text { al }^{24}\end{array}$ & $\begin{array}{l}\text { USA national } \\
\text { survey }\end{array}$ & Mail survey & $\begin{array}{l}\text { I,047 usable questionnaires } \\
\text { (response rate } 48 \% \text { ) } \\
\text { Commercially insured patients }\end{array}$ & $\begin{array}{l}\text { The response rate is relatively low } \\
\text { The study focused and included only commercially } \\
\text { insured patients; this limits the generalization of } \\
\text { findings to uninsured patients and government (state } \\
\text { or federal) insured patients }\end{array}$ \\
\hline $\begin{array}{l}\text { Papsdorf } \\
\text { et } \mathrm{al}^{25}\end{array}$ & Kansas, USA & Mail survey & $\begin{array}{l}\text { I79 participants responded to } \\
\text { the survey (response rate 50\%) } \\
\text { Patients using AEDs }\end{array}$ & $\begin{array}{l}\text { The study depended on patient self-reporting of } \\
\text { seizures rather than confirmed cases; also, the } \\
\text { breakthrough seizure and side effects might not be } \\
\text { due to AED switch } \\
\text { Nonresponse bias as the response rate is relatively low }\end{array}$ \\
\hline $\begin{array}{l}\text { Keenum } \\
\text { et } \mathrm{al}^{26}\end{array}$ & $\begin{array}{l}\text { Tennessee, } \\
\text { USA }\end{array}$ & $\begin{array}{l}\text { Interviewer- } \\
\text { administered } \\
\text { questionnaire-based } \\
\text { study }\end{array}$ & $\begin{array}{l}\text { I72 women were recruited in } \\
\text { this study (response rate } 80 \% \text { ) } \\
\text { Only female participants }\end{array}$ & $\begin{array}{l}\text { Generalization of the result is limited as the } \\
\text { participants were recruited from one single clinic } \\
\text { The study included only English-speaking women } \\
\text { aged } 2 \text { I-46 years; also, the study included only } \\
\text { participants that were enrolled in Medicaid (state } \\
\text { insurance program), so cannot be generalized to } \\
\text { other populations }\end{array}$ \\
\hline $\begin{array}{l}\text { Sewell } \\
\text { et } \mathrm{al}^{27}\end{array}$ & $\begin{array}{l}\text { Alabama, } \\
\text { USA }\end{array}$ & $\begin{array}{l}\text { Qualitative study } \\
\text { (focus group } \\
\text { discussion) }\end{array}$ & $\begin{array}{l}\text { Four focus groups with a total } \\
\text { of } 30 \text { participants } \\
\text { African-American in a rural area }\end{array}$ & $\begin{array}{l}\text { The study was conducted only in two counties in } \\
\text { Alabama } \\
\text { Participants were primarily women (93\%) and of a } \\
\text { higher educational level, so generalization of the } \\
\text { study findings is limited }\end{array}$ \\
\hline $\begin{array}{l}\text { Kohli and } \\
\text { Buller }{ }^{28}\end{array}$ & $\begin{array}{l}\text { Michigan, } \\
\text { USA }\end{array}$ & $\begin{array}{l}\text { Self-administered } \\
\text { questionnaire-based } \\
\text { study }\end{array}$ & $\begin{array}{l}\text { A total of I } 83 \text { out of } \\
200 \text { distributed questionnaires } \\
\text { were obtained (response rate } \\
92 \% \text { ) but only I } 60 \text { were valid } \\
\text { and completed questionnaire } \\
\text { and were included in the study }\end{array}$ & $\begin{array}{l}\text { There were no questions used in the survey to } \\
\text { check repeatability and accuracy of assessment } \\
\text { There were no questions related to health insurance } \\
\text { coverage and whether the coverage included OTC } \\
\text { medicines } \\
\text { The convenience sampling and characteristics of } \\
\text { the sample (ie, socioeconomic status and educational } \\
\text { status) and sample size limits generalization of the } \\
\text { results } \\
\text { Despite the instructions, some of the participants } \\
\text { might have responded to the survey questions as if } \\
\text { they were responding to prescription medicines } \\
\text { and not nonprescription medicines }\end{array}$ \\
\hline
\end{tabular}


Table I (Continued)

\begin{tabular}{lllll}
\hline Study & Country & Methods & Population and sample size & Limitations \\
\hline Pereira & Ontario, & Self-administered & A total of $8 \mathrm{I}$ patients answered & The response rate was very low; moreover, sampling \\
et al $^{29}$ & Canada & questionnaire-based & the survey (response rate $16.2 \%)$ & bias might be another limitation, as those patients \\
& & study & Patients on warfarin more interest in generic substitution or with & some concerns were more likely to participate \\
\hline
\end{tabular}

Abbreviations: AED, antiepileptic drug; OTC, over-the-counter.

to the perceived risk, ie, the higher the risk, the greater the cost saving required. ${ }^{20}$

Participants in a study by Sansgiry et $\mathrm{al}^{21}$ in Houston, Texas, had a slightly more positive perception regarding generic substitution. Although many participants (61\%) supported generic substitution, some participants (22\%) considered that generic substitution prevented them from getting the medicines prescribed by their physicians, and a similar percentage $(20 \%)$ stated that it prevented them from having the best medicines. Regarding the effectiveness, quality, safety, and side effect profiles of generic medicines, $19 \%$ and $20 \%$ believed that generic substitution led to less effective and lower quality medicines, respectively, while $61 \%$ believed that side effects would not increase because of generic substitution. Moreover, in this study, less than half of participants $(46 \%)$ requested generic medicines from their pharmacists to substitute their brand medicines. In this study, there was a statistically significant positive correlation between participants' perceptions towards generic substitution and their attitude towards generic medicines $(r=0.63$, $P<0.001)$. Also, there was a statistically significant positive correlation between participants' perceptions of generic substitution and their willingness to ask their pharmacists for a generic substitution ( $r=0.40, P<0.001)$. Overall, consumers in this study had a slightly more positive attitude towards generic medicines. However, the study still identified a significant proportion of consumers with negative or neutral attitudes towards generic medicines. ${ }^{21}$

Iosifescu et $\mathrm{al}^{22}$ conducted a study in New York to evaluate the beliefs of elderly adults ( $\geq 65$ years) who were enrolled in Medicare (the federal health insurance program for elderly and disabled adults in the USA) about generic medicines. In this study, $45.8 \%$ strongly or somewhat agreed that generic medicines are as safe as brand medicines. Similarly, $46.6 \%$ strongly or somewhat agreed that generic medicines are as effective as brand medicines. In this study, only $11.6 \%$ strongly or somewhat agreed that generic medicines produce more side effects than brand medicines. Negative beliefs and perceptions about generic medicines were associated with non-white race, a lower level of education, low income, having Medicaid insurance coverage, low health literacy, and poor communication skills on the part of physicians. The authors concluded that many low-income elderly adults, especially African Americans and those with inadequate health literacy, have negative beliefs about generic medicines. ${ }^{22}$

Shrank et $\mathrm{al}^{23}$ conducted a national survey with commercially insured patients in the USA. Most participants $(94 \%)$ believed that generic medicines are cheaper than their counterpart brand medicines. More than $70 \%$ believed that generic medicines are better value than brand medicines. Despite these two facts reflecting an appreciation of generic medicines, only $37.6 \%$ preferred to use generic medicines themselves. In this study, $29.9 \%$ of participants agreed that brand medicines are more effective than generic medicines. Less than $10 \%$ of participants believed that generic medicines produce more side effects than brand medicines. Regarding communication with health care providers about generic medicines, $53.7 \%$ of participants mentioned that their physicians never or seldom talked to them about generic medicines, while $52 \%$ mentioned that pharmacists never or seldom talked to them about generic medicines. The authors concluded that although most participants are aware of the value and economic benefit of generic medicines, few are willing to use generic medicines themselves. ${ }^{23}$

In another paper, Shrank et $\mathrm{al}^{24}$ investigated the relationship between patients' beliefs and communication about generic medicines and their actual use of generic medicines. The study findings showed that, of five domains, ie, general preferences for generic medicines, effectiveness and safety of generic medicines, generic cost/value, feeling comfortable with generic substitution, and communication with health care providers about generic medicines, only two domains (feeling comfortable with generic substitution and communication with health care providers about generic medicines) were significantly associated with the use of generic medicines in the fully adjusted model. Therefore, the authors concluded that educational efforts that concentrate on these two factors might be more effective for increasing the use and acceptance of generic medicines. ${ }^{24}$

Papsdorf et $\mathrm{al}^{25}$ conducted a study in Kansas to explore the experiences and attitudes of patients towards generic 
antiepileptic drugs (AEDs) and generic substitution policy. The study findings showed that the majority of patients $(80.2 \%)$ were aware of the existence of some generic AEDs. Also, more than half of the participants (57.1\%) mentioned that they had used a generic AED. Among those who mentioned having used generic AEDs, 27.8\% reported a breakthrough seizure and $34 \%$ reported experiencing side effects that they thought were related to the generic substitution. Due to these negative experiences, $31.2 \%$ switched back to original brand medicines. In this study, $78.7 \%$ of participants were concerned about the generic substitution policy that allows pharmacists to make a generic substitution without the patient's consent or their physician's approval. Moreover, 53.3\% of this sample of patients with epilepsy expressed concerns over the increasing utilization of generic AEDs. ${ }^{25}$

Keenum et $\mathrm{a}^{26}$ conducted a study using a convenience sample of women visiting a gynecology health clinic and currently enrolled in US TennCare (Medicaid). In this study, most (97.6\%) of the women interviewed believed that generic medicines are cheaper than their counterpart brand medicines. More than half $(60.5 \%)$ believed that generic medicines are better value than brand medicines. Despite these two facts indicating an appreciation of generic medicines, only $45.3 \%$ preferred to use generic medicines themselves. In this study, most women (86.6\%) believed that generic medicines have the same side effect profile as the brand medicines and $76.7 \%$ stated that they have the same effectiveness. Communication and discussion with health care providers about generic medicines was uncommon, with only $29.7 \%$ and $35.5 \%$ of participants, respectively, stating that their physician and pharmacist talked to them about generic medicines. Therefore, the authors concluded that frequent discussion and communication between health care professionals and patients about generic medicines needs to be encouraged, and that awareness about the value and benefits of generic medicines does not translate into a preference for personal use of generic medicines. ${ }^{26}$

Sewell et al ${ }^{27}$ conducted a qualitative study in Alabama that consisted of four focus groups including 30 participants, and found that most participants believed generic medicines to be less effective than brand medicines. Conversely, fewer participants expressed concerns regarding differences in the side effect profile between generic medicines and brand medicines. Interestingly, in this qualitative study, some participants considered brand medicines to be "real medicines" while generic medicines are not. Moreover, participants were willing to use generic medicines for minor illnesses but were hesitant to use them for more serious conditions.
Participants also had the perception that generic medicines are cheaper, second-choice medicines that poor or low income patients "have to settle for". ${ }^{27}$

Kohli and Buller ${ }^{28}$ conducted a study in Michigan to evaluate perceptions of generic and branded over-the-counter (OTC) medicines and to determine factors influencing the decision of participants to use generic or brand medicines. The vast majority of participants believed that generic and brand OTC medicines are of the same safety (91\%) and efficacy (82.5\%) and pass through the same US Food and Drug Administration (FDA) approval process (91\%). Almost half of the participants (50.6\%) often or almost always used generic OTC medicines over their equivalent OTC brand. However, $24.4 \%$ were willing to pay more for the OTC brand medicine and $71.9 \%$ stated that they stick to the same brands of OTC medicine. The influencing factor when selecting generic OTC medicines was their low cost. However, the influencing factors for taking an OTC brand medicine were advertising, duration of effect, severity of illness, relief of multiple symptoms, and preferred manufacturer. ${ }^{28}$

Pereira et $\mathrm{al}^{29}$ conducted a study in Ontario with patients on warfarin to evaluate their perceptions of generic warfarin and generic substitution. In this study, $63 \%$ of patients were on Coumadin $^{\circledR}$ (Bristol-Myers Squibb, St Laurent, Quebec, QC, Canada) while the rest (37\%) were on generic warfarin. In general, $42.5 \%$ were aware of the availability of generic medicines and $46.9 \%$ were comfortable with using generic medicines. Specifically with regard to warfarin, $51.9 \%$ stated that they were happy with the current brand of warfarin they were using and $33.3 \%$ reported that they would feel comfortable using a generic warfarin instead of the branded product, Coumadin. However, $17.2 \%$ thought that generic warfarin is not as effective as the brand version and a similar percentage (17.2\%) thought that generic warfarin is not as safe as the brand version. In this study, there were no statistically significant differences between responses of participants in terms of age or sex. However, there were statistically significant differences between the responses of patients who were on original brand warfarin and the patients who were on generic brands of warfarin. A larger proportion of patients taking generic warfarin were aware of the availability of generic medicines in the market, comfortable taking generic medicines, perceived generic warfarin as having the same effectiveness and safety as the original brand, and aware of the regulatory and registration requirements..$^{29}$

\section{Studies from Australia}

Five studies from Australia and New Zealand were identified. A summary of the characteristics of these studies 
is presented in Table 2. Hassali et al ${ }^{30}$ conducted a qualitative study of 16 consumers in Melbourne, Australia, to explore consumers' perceptions of generic medicines and to determine barriers to the use of generic medicines. The study findings showed that some patients were not familiar with the term "generic medicines". The main facilitators of generic acceptance were its cost and recommendation by health care professionals, while the barriers were the preferences and influence of medical doctors, concerns about the side effects of generic medicines, lack of adequate information about generic medicines, and potential confusion due to use of different brands of medicines. Thus, the authors concluded that educational efforts by health care professionals and governments need to be made to educate society and patients about the safety and efficacy of generic medicines. ${ }^{30}$
Bulsara et $\mathrm{al}^{31}$ conducted a qualitative study in Western Australia to explore the perceptions and views of elderly patients' ( $\geq 65$ years) on generic medicines. The study findings showed that many participants mistrusted generic medicines and were confused about them. Some participants believed that generic medicines are of inferior quality compared with brand medicines. Also, many participants were not aware of the differences between generic medicines and brand medicines, including aspects such as active ingredients, and reported some confusion regarding the terminology and names of the brands used. Some participants suggested that the names of active ingredients need to be highlighted on the packaging and labeling of medicines, rather than the trade names. Thus, a lack of uniformity in packaging and labeling also adds to the confusion, especially for elderly patients who are often on multiple medicines and might

Table 2 Summary of studies included in the review investigating patients' perceptions and acceptance of generic medicines in Australia and New Zealand

\begin{tabular}{|c|c|c|c|c|}
\hline Study & Country & Methods & Population and sample size & Limitations \\
\hline Hassali et $\mathrm{al}^{30}$ & $\begin{array}{l}\text { Melbourne, } \\
\text { Australia }\end{array}$ & $\begin{array}{l}\text { Qualitative study } \\
\text { using indepth } \\
\text { individual interviews }\end{array}$ & 16 medicine consumers & $\begin{array}{l}\text { The study was conducted in one state only } \\
\text { Therefore, generalization to consumers in other } \\
\text { states may not be possible } \\
\text { The study included only English-speaking } \\
\text { consumers while consumers from non-English } \\
\text { speaking backgrounds were not included }\end{array}$ \\
\hline Bulsara et $\mathrm{al}^{31}$ & Western Australia & $\begin{array}{l}\text { Qualitative study } \\
\text { involving consumer } \\
\text { forums, consumer } \\
\text { panel, and focus } \\
\text { group }\end{array}$ & $\begin{array}{l}\text { The study involved } 3 \text { consumer } \\
\text { forms ( } n=104) \text {, from which one } \\
\text { consumer panel }(n=10) \text { and } \\
6 \text { focus groups }(n=58) \text { arose } \\
\text { It included only elderly patients } \\
\text { ( } \geq 65 \text { years), with more interest } \\
\text { in patients with chronic disease }\end{array}$ & $\begin{array}{l}\text { The participants in focus groups had already } \\
\text { attended the consumer forums about generic } \\
\text { medicines; this might have increased their } \\
\text { awareness about issues surrounding generic } \\
\text { medicines } \\
\text { Participation in the focus group was self-selecting } \\
\text { As such, more of those who are more familiar } \\
\text { with the topic might have been included }\end{array}$ \\
\hline Ibrahim et $\mathrm{al}^{32}$ & $\begin{array}{l}\text { Adelaide, South } \\
\text { Australia }\end{array}$ & $\begin{array}{l}\text { A cross-sectional } \\
\text { self-administered } \\
\text { questionnaire-based } \\
\text { study }\end{array}$ & $\begin{array}{l}\text { A total of } 503 \text { patients } \\
\text { participated in the study } \\
\text { (response rate } 99 \% \text { ) }\end{array}$ & $\begin{array}{l}\text { The study was conducted in one state and thus } \\
\text { generalization of findings to other states in } \\
\text { Australia might not be possible } \\
\text { As it was a self-administered anonymous survey, } \\
\text { response to the item related to consumer's } \\
\text { preference was not further clarified }\end{array}$ \\
\hline Ngo et $\mathrm{al}^{33}$ & $\begin{array}{l}\text { South Australia } \\
\text { and the Northern } \\
\text { Territory }\end{array}$ & Mail survey & $\begin{array}{l}47 \text { questionnaires were } \\
\text { returned (response rate 6.7\%) } \\
\text { Patients with epilepsy }\end{array}$ & $\begin{array}{l}\text { The low response rate of the study is a major } \\
\text { limitation. The sample size did not cover all states, } \\
\text { therefore generalization of the study findings is } \\
\text { not possible } \\
\text { The sample might not be representative of epilepsy } \\
\text { patients as it is more likely that those who are } \\
\text { more interested in the topic or more motivated } \\
\text { responded to the survey }\end{array}$ \\
\hline Babar et $\mathrm{al}^{34}$ & $\begin{array}{l}\text { Auckland, New } \\
\text { Zealand }\end{array}$ & $\begin{array}{l}\text { A cross-sectional } \\
\text { self-administered } \\
\text { questionnaire-based } \\
\text { study }\end{array}$ & $\begin{array}{l}\text { A total of } 44 \text { I consumers } \\
\text { participated in the study } \\
\text { (response rate } 76 \% \text { ) } \\
\text { General population }\end{array}$ & $\begin{array}{l}\text { The study included only those consumers who } \\
\text { visited and entered inside the community } \\
\text { pharmacy and it was also conducted during the } \\
\text { working hours of weekdays, so those part-time } \\
\text { workers might be overrepresented; also, those } \\
\text { who are visiting community pharmacies might be } \\
\text { different to the general population }\end{array}$ \\
\hline
\end{tabular}


have multiple substitutions. The authors concluded that the concerns raised by senior patients need to be addressed, otherwise the uptake of generic medicines by this group of patients would not improve. ${ }^{31}$

Ibrahim et $\mathrm{al}^{32}$ conducted a study in Adelaide, South Australia, to evaluate patients' perceptions and knowledge of generic medicines. In this study, about $67 \%$ mentioned that they rarely requested generic substitution for their prescription medicines at their community pharmacy. Almost half of the participants (47\%) mentioned that they needed more information about generic medicines. Also, 27.2\% mentioned that they were not informed about generic substitution and generic medicines by their health care providers, ie, physicians and pharmacists. In this study, $52 \%$ of patients disagreed that generic medicines are of inferior quality and $49 \%$ disagreed that brand medicines are more effective than generic versions, while 53\% disagreed that generic medicines produce more side effects. Overall, only $29.7 \%$ of participants agreed that they would take generic medicines rather than brand medicines. The authors concluded that while some patients lack adequate knowledge about generic medicines, many did not prefer the use of generic medicines but were neutral towards them. ${ }^{32}$

Ngo et al $^{33}$ conducted a study of patients with epilepsy in South Australia and in the Northern Territory. In this study, the majority of respondents stated that pharmacists should only perform generic substitution for their AEDs with their consent $(87.2 \%)$ and with the consent of their doctors $(63.8 \%)$. In this study, $80.8 \%$ felt comfortable about asking their doctors to prescribe only brand medicines for their AEDs, and 68.0\% felt uncomfortable using generic medicines for treatment of their epilepsy. Moreover, potential cost savings would make only $23.4 \%$ prefer to use generic AEDs. In this study, the majority of participants expressed concern about the effectiveness (70.2\%) and safety (55.4\%) of generic AEDs. For generic medicines in general, 44.6\% expressed concern about use of generic medicines for shortterm medical conditions. ${ }^{33}$

\section{Study from New Zealand}

Babar et $\mathrm{al}^{34}$ conducted a study in Auckland, New Zealand, to explore the perceptions, knowledge, and attitudes of consumers regarding generic medicines. Their findings showed that $51.6 \%$ were familiar with the term "generic medicine". In this study, there was a statistically significant association between education, age, and ethnicity of participants and knowledge of generic medicines, with participants of older age, with a lower level of education, and of certain ethnic origin having a lower level of knowledge about generic medicines. In this study, 36.0\% reported that they felt uncomfortable if the physical characteristics (color and shape) of their medicine changed and 16.2\% reported having been told by their health care professionals to stay on the same brand. In the event of a minor illness (eg, hay fever), $78 \%$ reported they would accept a generic substitution on the recommendation of the pharmacist. This study also showed that those with a better knowledge of generic medicines and those with a higher level of education were more likely to accept generic substitution. For more serious conditions (eg, diabetes), only 58.7\% would accept generic substitution. While there was no association between demographic characteristics and acceptance of generic substitution for serious illness, there was a relationship between knowledge about generic medicines and acceptance of generic substitution for serious illness. The authors concluded that many participants in their study had misconceptions about generic medicines. The level of knowledge about generic medicines and recommendations by health care professionals were the determinant factors for use of generic medicines and acceptance of generic substitution. ${ }^{34}$

\section{Studies from Asia}

Six studies were identified from Asia. A summary of the characteristics of these studies is presented in Table 3. Al-Gedadi et $\mathrm{al}^{35}$ conducted a study in Penang, Malaysia, to evaluate consumers' perceptions and awareness of generic medicines. In this study, only $28.3 \%$ consumers knew the term "generic medicines". Moreover, only $28 \%$ knew that generic medicines can be available under different names on the market. For those who were familiar with generic medicines, most (59.8\%) knew about them from their health care professionals, ie, pharmacists and physicians. The vast majority $(80.6 \%)$ indicated that there is a need to educate patients about generic medicines. Many participants had misconceptions about generic medicines, with a considerable percentage indicating that generic medicines are of inferior quality (38.9\%), less effective (34.8\%), and may produce more side effects $(31.2 \%)$ compared with the original brand medicines. In this study, $75 \%$ of participants reported that they would use a generic medicine on the recommendation of their health care professional. The authors concluded that many consumers lack knowledge about generic medicines. ${ }^{35}$

Thomas and Vitry ${ }^{36}$ conducted a study in Kuala Lumpur and Selangor, Malaysia, to explore consumers' knowledge about generic medicines and their willingness to use them. 
Table 3 Summary of studies included in the review investigating patients' perceptions and acceptance of generic medicines in Asia

\begin{tabular}{|c|c|c|c|c|}
\hline Study & Country & Methods & Population and sample size & Limitations \\
\hline Al-Gedadi et $\mathrm{al}^{35}$ & Penang, Malaysia & $\begin{array}{l}\text { A self-administered } \\
\text { questionnaire-based } \\
\text { study }\end{array}$ & $\begin{array}{l}\text { A total of } 396 \text { valid } \\
\text { questionnaires were included } \\
\text { in the study (convenience } \\
\text { sample) }\end{array}$ & $\begin{array}{l}\text { The small sample size of the study and } \\
\text { convenience sampling technique limit } \\
\text { generalization of results } \\
\text { The study was conducted in one state; } \\
\text { hence, results cannot be generalized to } \\
\text { the whole country }\end{array}$ \\
\hline Hoshi and Kimura ${ }^{38}$ & Kanto area of Japan & $\begin{array}{l}\text { A cross-sectional } \\
\text { survey }\end{array}$ & $\begin{array}{l}457 \text { outpatients (a convenience } \\
\text { sample) }\end{array}$ & $\begin{array}{l}\text { Limitations were not mentioned by the } \\
\text { authors }\end{array}$ \\
\hline Thomas and Vitry ${ }^{36}$ & $\begin{array}{l}\text { Kuala Lumpur and } \\
\text { Selangor, Malaysia }\end{array}$ & $\begin{array}{l}\text { An interviewer- } \\
\text { administered } \\
\text { questionnaire-based } \\
\text { study }\end{array}$ & $\begin{array}{l}\text { A total of } 203 \text { consumers } \\
\text { were interviewed }\end{array}$ & $\begin{array}{l}\text { The study was conducted in two regions } \\
\text { of Malaysia; therefore, it is not possible } \\
\text { to generalize the results to other parts } \\
\text { of the country; in addition, the study } \\
\text { was conducted in urban areas and rural } \\
\text { communities were not represented } \\
\text { The participation rate was not } \\
\text { calculated and those who refused to } \\
\text { take part might have different views } \\
\text { Many participants were not obtaining } \\
\text { prescription medicines from the } \\
\text { pharmacy, hence, they might have less } \\
\text { experience with generic medicines }\end{array}$ \\
\hline Kobayashi et al ${ }^{39}$ & 8 regions in Japan & $\begin{array}{l}\text { A self-administered } \\
\text { questionnaire-based } \\
\text { study }\end{array}$ & $\begin{array}{l}\text { A total of } 1,215 \text { completed } \\
\text { questionnaires were obtained } \\
\text { (response rate } 90.3 \% \text { ) } \\
\text { General patients }\end{array}$ & $\begin{array}{l}\text { Limitations were not mentioned by the } \\
\text { authors }\end{array}$ \\
\hline Ahire et $\mathrm{al}^{40}$ & $\begin{array}{l}\text { Maharashtra and } \\
\text { Rajasthan, India }\end{array}$ & $\begin{array}{l}\text { A cross-sectional } \\
\text { survey }\end{array}$ & $\begin{array}{l}\text { I00 participants of science back } \\
\text { ground and } 100 \text { participants } \\
\text { from general (non-science) } \\
\text { background }\end{array}$ & $\begin{array}{l}\text { Limitations were not mentioned by the } \\
\text { authors }\end{array}$ \\
\hline Abzakh et $\mathrm{al}^{37}$ & $\begin{array}{l}\text { Klang Valley, } \\
\text { Malaysia }\end{array}$ & $\begin{array}{l}\text { A self-administered } \\
\text { questionnaire based } \\
\text { study }\end{array}$ & $\begin{array}{l}\text { A total of } 456 \text { consumers } \\
\text { (response rate } 91.2 \% \text { ) } \\
\text { Consumers resistant to } \\
\text { generic medicines }\end{array}$ & $\begin{array}{l}\text { The study used a convenience } \\
\text { sampling technique that limits } \\
\text { generalization of the results } \\
\text { The study design was cross-sectional; } \\
\text { hence, the changeover time in the } \\
\text { behavior towards generic medicines } \\
\text { cannot be assessed }\end{array}$ \\
\hline
\end{tabular}

In this study, only $32.5 \%$ of consumers were aware of the concept and meaning of the term "generic medicines". Of those consumers who were aware, $51 \%$ described them as "cheaper" while $18 \%$ described them as "non-original or nongenuine", $18 \%$ described them as "locally made medicines or made by a different company" and only $13 \%$ described them as "a different brand of medicine with the same content". Only $42 \%$ had experience of generic medicines while $13 \%$ were not sure and $45 \%$ did not use generic medicines. The main reasons given by those who used generic medicines were that they were the same medicine with the same effect $(40 \%)$, cheaper $(36 \%)$, or were supplied by their hospital $(21 \%)$. The majority of those who had not used generic medicines (55\%) reported that they were not willing to use them. The main reasons for refusing generic medicines were primarily related to negative perceptions, with $27 \%$ believing that generic medicines are less effective, $27 \%$ thinking that they have a low safety profile, $25 \%$ thinking that they are of a lower quality (due to their cheaper price), and $26 \%$ reporting that they did not have enough knowledge about generic medicines to decide. The authors concluded that many consumers in Malaysia are not aware of generic medicines. ${ }^{36}$

Abzakh et $\mathrm{a}^{37}$ investigated the relationship between risk dimensions (financial risk, performance risk, physical risk, time risk, social risk, and psychological risk) and resistance to use of generic medicines in Klang Valley, Malaysia. In this study, 456 consumers who refused generic medicines and purchased original brands completed a self-administered questionnaire (response rate 91.2\%). The results showed that physical risk (defined as "concerns about dangers to the individuals' health and to their physical energy resulting from using generic drugs") and performance risk (defined as 
"discrepancy between the product performance and consumer expectation and can be considered as a concern that the purchased product might not perform as the consumer expects and so will not deliver the benefits as perceived") had a positive relationship with resistance to use of generic medicines. In this study, other risk dimensions including financial risk, time risk, social risk, and psychological risk were not significantly related to resistance to generic medicines. ${ }^{37}$

Hoshi and Kimura ${ }^{38}$ conducted a survey in the Kanto area of Japan to explore the perceptions and awareness of outpatients' and medical staff regarding generic medicines (only patient results are reported here). In this study, $82.2 \%$ of outpatients surveyed knew about generic medicines. However, only $11.3 \%$ reported having used them, and $65.4 \%$ did not know the price difference between generic medicines and their counterpart brand medicines. Approximately $60 \%$ of participants reported that they would be willing to accept generic substitution if generic medicines were cheaper. The three main reasons for outpatients not using generic medicines were: not prescribed by their physicians, lack of awareness of generic medicines, and concerns about use of generic medicines. The authors concluded that educational efforts need to continue using different methods, including the media, and that health care professionals need to support use of generic medicines by counseling patients and recommending that their patients use them. ${ }^{38}$

Kobayashi et al ${ }^{39}$ conducted a study in Japan to evaluate patients' understanding and attitudes towards generic substitution and their willingness to use generic medicines. Their results showed that $68.4 \%$ of patients knew the term "generic drugs". However, only a small percentage (18.4\%) of participants who knew of generic medicines had an experience of generic substitution. Of those who knew the term, $54 \%$ were willing to accept generic substitution. The majority of the respondents had the correct knowledge that generic medicines and brand medicines contain the same active ingredients $(71.1 \%)$ and that generic medicines are less expensive ( $86 \%$ ). However, less than $50 \%$ of respondents were aware of the price difference among generic medicines, the possibility of generic substitution at community pharmacies, and other aspects related to generic medicines, such as additives. The main reasons given by those who accepted generic substitution $(n=142)$ were recommendation by physicians (48.6\%) and pharmacists (33.1\%). In this study, younger patients ( $<60$ years) had more awareness of generic medicines than older patients ( $81.9 \%$ versus $53.4 \%, P<0.01$ ). Also, women were more aware of generic medicines than men (70.4\% versus $64.1 \%, P<0.05)$. For willingness to accept generic substitution, there was no statistically significant association between demographic variables (sex, age, or region) and willingness to accept. However, patients with experience of generic substitution were more willing than others to accept it. The authors concluded that many Japanese patients have a low perception of generic medicines. Also, given that patients were only aware of some points, awareness campaigns should cover all other aspects of generic medicines. Health care professionals need to have the correct knowledge about generic medicines because most patients relied on their advice regarding taking them. ${ }^{39}$

Ahire et a $1^{40}$ conducted a survey of 100 participants with a science background and 100 participants from the general population in Maharashtra and Rajasthan, India, to evaluate their understanding of and preferences for generic medicines. For the consumers with a science background, $60.86 \%$ stated that generic medicines had the same effectiveness and $39.21 \%$ stated that they adhere to the same FDA guidelines as the brand medicines. However, $73.92 \%$ were not currently using generic medicines. Moreover, $86.95 \%$ of participants had never been recommended to switch to a generic medicine by their health care professional (physician or pharmacist). For consumers without a science background, $75 \%$ stated that they were familiar with generic medicines. Interestingly, only $8.3 \%$ stated that the cheaper brands of the same medicine (ie, generic versions) had the same effectiveness as the more expensive brands. Further, $83.33 \%$ stated that generic medicines are not as safe as brand medicines. Importantly, $72 \%$ reported that they would switch to a generic medicine on the recommendation of their physician. The authors concluded that, because most patients follow their doctor's prescription, most would not accept generic substitution. Hence, physicians need to prescribe generic medicines as part of promoting them to their patients. ${ }^{40}$

\section{Studies from the Middle East}

Five Middle Eastern studies were identified. A summary of the characteristics of these studies is shown in Table 4. Sharrad and Hassali ${ }^{41}$ conducted a qualitative study exploring consumers' perceptions and knowledge of generic medicines in Basra, Iraq. This study showed that participants were not familiar with the term "generic medicine" and that the term "commercial medicine" is the most common term used to describe generic medicines. Moreover, most participants were not aware of the concept of generic medicines in terms of active ingredients and scientific names. Cheaper price, availability of generic medicines in pharmacies, recommendation by health care professionals, country of origin 
Table 4 Summary of studies included in the review investigating patients' perceptions and acceptance of generic medicines in the Middle East

\begin{tabular}{|c|c|c|c|c|}
\hline Study & Country & Methods & Population and sample size & Limitations \\
\hline $\begin{array}{l}\text { Sharrad and } \\
\text { Hassali }^{41}\end{array}$ & Basra, Iraq & $\begin{array}{l}\text { A qualitative study } \\
\text { using semi-structured } \\
\text { face-to-face interviews }\end{array}$ & $\begin{array}{l}\text { A purposive sample of } \\
\text { I } 4 \text { medicine consumers } \\
\text { General population }\end{array}$ & $\begin{array}{l}\text { The study was conducted in one city and hence it } \\
\text { cannot confidently be generalized to the whole } \\
\text { country; the study is also limited by the topics } \\
\text { covered and questions addressed in the interview } \\
\text { and the analysis and coding process of the } \\
\text { researcher }\end{array}$ \\
\hline Toklu et $\mathrm{al}^{42}$ & $\begin{array}{l}\text { Istanbul, } \\
\text { Turkey }\end{array}$ & $\begin{array}{l}\text { A cross-sectional } \\
\text { questionnaire-based } \\
\text { study }\end{array}$ & The study included IOI patients & The limitation was the small sample size \\
\hline $\begin{array}{l}\text { El-Dahiyat and } \\
\text { Kayyali }^{43}\end{array}$ & Jordon & $\begin{array}{l}\text { A cross-sectional } \\
\text { self-administered } \\
\text { questionnaire-based } \\
\text { study }\end{array}$ & $\begin{array}{l}\text { A total of } 400 \text { patients } \\
\text { participated in the study } \\
\text { (response rate } 80 \% \text { ) } \\
\text { Patients with chronic disease } \\
\text { only }\end{array}$ & $\begin{array}{l}\text { The limitations were not mentioned by the } \\
\text { authors }\end{array}$ \\
\hline Al Ameri et al $^{44}$ & $\begin{array}{l}\text { United Arab } \\
\text { Emirates }\end{array}$ & $\begin{array}{l}\text { A cross-sectional } \\
\text { self-administered } \\
\text { questionnaire-based } \\
\text { study }\end{array}$ & $\begin{array}{l}\text { A total of } 188 \text { renal patients } \\
\text { were recruited from two } \\
\text { hospitals } \\
\text { Only renal patients }\end{array}$ & $\begin{array}{l}\text { The study was conducted in only two hospitals, } \\
\text { so it might not be possible to generalize the } \\
\text { results to other parts of the country } \\
\text { There were missing responses to many of the } \\
\text { statements in the survey, which might have } \\
\text { affected the results }\end{array}$ \\
\hline Albarraq $^{45}$ & $\begin{array}{l}\text { Taif, Saudi } \\
\text { Arabia }\end{array}$ & $\begin{array}{l}\text { An interviewer- } \\
\text { administered } \\
\text { questionnaire-based } \\
\text { study }\end{array}$ & $\begin{array}{l}\text { A total of } 450 \text { participants were } \\
\text { included in the study; } \\
17.1 \% \text { were medical professionals }\end{array}$ & $\begin{array}{l}\text { The study was conducted in one city; thus, findings } \\
\text { cannot be generalized to other parts of the country } \\
\text { The study employed a convenience sampling } \\
\text { technique; also, response rate was not calculated } \\
\text { and accordingly the percentage of those who } \\
\text { declined to participate is not known as they may } \\
\text { differ from those who were willing to participate } \\
\text { The study included I7.I\% participants from the } \\
\text { medical field. Thus, the study included not only the } \\
\text { general public but also health care professionals }\end{array}$ \\
\hline
\end{tabular}

of the medicine, and reputation of the drug company were important facilitators of generic medicine use in this study population. Barriers to generic medicines were doctors' reluctance to prescribe generic medicines, potential confusion due to use of different medicine brands, stability and consistency of using one brand, and the presence of counterfeit medicines. Most participants reported that they would accept generic substitution only with the approval of their physicians, with only a few stating that they would accept a pharmacist's recommendation. In this study, education on generic medicines by both physicians and pharmacists seemed to be the most effective way to promote generic medicines to patients. The authors concluded that there is a gap in consumers' knowledge about generic medicines in Iraq. Therefore, there is a need for education and interventions to better inform patients about the uses and benefits of generic medicines. ${ }^{41}$

Toklu et a ${ }^{42}$ conducted a study in Istanbul, Turkey, to evaluate the knowledge and attitudes of community pharmacists, physicians, and patients towards generic medicines (only the results related to patients are reported here). In terms of efficacy, only $24 \%$ of patients indicated that generic medicines are not different to brand medicines, $53 \%$ indicated that some generic medicines are different, $7 \%$ felt that all generic medicines are different, and $14 \%$ had no idea about the difference. Ten percent and $26 \%$, respectively, reported that they would "directly accept" generic substitution if it was recommended by pharmacists and physicians. Approximately $70 \%$ needed to be persuaded before they would accept generic medicines. However, only $16 \%$ would strictly refuse generic substitution by pharmacists while $3 \%$ would do so even if this was initiated by the physician. There was no relationship between acceptance of generic medicines and age, sex, and income. However, there was a negative association between acceptance of generic medicines and education level, ie, more highly educated patients were less likely to accept generic substitution. The authors concluded that this study population held misconceptions and had insufficient knowledge about generic medicines, and identified a need for patient education about generic medicines. ${ }^{42}$ 
El-Dahiyat and Kayyali ${ }^{43}$ conducted a study in Jordan to evaluate perceptions about generic medicines in patients with chronic illness. The study findings showed that the majority of participants (63.5\%) would accept generic substitution only at their own request, with $27.75 \%$ reporting that they preferred to be prescribed well-known brands. Moreover, $36 \%$ believed that a more expensive medicine is a better one. However, most participants (79\%) stated that the cost of the medicine should be taken into consideration when prescribing. Most participants (83\%) considered that medicine prices in Jordan are generally very expensive, and $78.25 \%$ stated that use of generic medicines would lead to substantial cost savings. Thus, the authors concluded that the main factor facilitating utilization of generic medicine is their cheaper price, given that other medicines are much more expensive. ${ }^{43}$

Al Ameri et $\mathrm{al}^{44}$ conducted a study of renal patients in the United Arab Emirates to explore their knowledge and awareness of generic medicines and generic substitution. In this study, $60 \%$ of participants indicated that they were familiar with the terms generic medicines and brand medicines. However, only $33 \%$ believed that generic medicines are always equivalent to brand medicines. Sixty-four percent of participants were aware of generic substitution. Twenty-nine percent were taking generic prescription medicines, 39\% were not taking any, and 32\% were not sure. Only $33 \%$ thought that use of generic medicines would not influence their compliance with medication. In the event of a minor condition, $50.27 \%$ of patients reported they would accept generic substitution, while only $24 \%$ reported that they would do so for a chronic illness. The majority of participants (69\%) would accept generic substitution if recommended by their hospital physician. Almost half of the participants (47\%) would not accept the generic version of cyclosporine if it became available on the local market. The authors concluded that many patients have negative perceptions about generic medicines and generic substitution. ${ }^{44}$

Albarraq ${ }^{45}$ conducted a study in Taif, Saudi Arabia, to explore consumer perceptions of generic medicines. Most participants (62.7\%) reported that they preferred to use brand medicines rather than generic medicines. Only $34.9 \%$ were willing to accept generic substitution on the recommendation of a pharmacist. The majority stated that they would need to confirm with their physicians before accepting generic medicines, either for all medicines (49.6\%) or for some (15.6\%). In this study, $60.9 \%$ stated that generic medicines were always or sometimes of low efficiency compared with brand medicines. Only $37.1 \%$ disagreed that generic medicines cause more side effects than brand medicines. The author concluded that consumers in Taif had misconceptions about generic medicines and generic substitution. ${ }^{45}$

\section{Studies from Europe}

Twenty-four European studies were identified. A summary of the characteristics of these studies is presented in Table 5 . Heikkilä et $\mathrm{a}^{46}$ conducted a study in Finland to explore customers' and physicians' attitudes, views, opinions, and experiences during the first year after introduction of mandatory generic substitution in 2003 (physicians' results are not reported here). Two separate studies were conducted with consumers. One study targeted consumers who refused generic substitution and the other study included customers who accepted generic substitution at least once. The main reasons for refusing generic substitution were a positive experience with their current brands of medicines (65\%), wanting to discuss with their physicians before accepting generic medicine ( $42 \%)$, and the price difference being too small (35\%). In this group, $43 \%$ agreed that cheaper medicines are effective and $63 \%$ disagreed that interchangeable medicines (mostly generic medicines) are not safe. Consumers under 60 years of age were more likely than older consumers to consider interchangeable medicines as being effective and safer. In the second study, the main reasons for accepting generic substitution were the cost saving ( $84 \%)$ and recommendation by the pharmacist $(72 \%)$. In this group, $66 \%$ considered that cheaper medicines are effective and $77 \%$ disagreed that interchangeable medicines are not safe. Consumers under 60 years of age were more likely than their older counterparts to consider interchangeable medicines to be effective. ${ }^{46}$

Halme et $\mathrm{al}^{47}$ conducted an adaptive conjoint analysis questionnaire-based study in Finland to evaluate the preferences of patients for generic and branded OTC analgesic medicines. In this study, the most important considerations when selecting an OTC analgesic for headache were price and brand (33\%), time until onset of action (25\%), and source of information (25\%), with only $17 \%$ considering place of purchase to be important. The participants were classified into five clusters of characteristics for analysis: cluster 1 (rapid onset, 19\%); cluster 2 (low price or price conscious, 18\%), cluster 3 (brand or brand loyal, 16\%); cluster 4 (rationale low price, rapid onset, and pharmacist and physician as the preferred source of information, 27\%); and cluster 5 (authorityoriented, pharmacy is the preferred place of purchase, and pharmacists and physicians are the preferred source of information, 20\%). The authors concluded that almost half of the participants were sensitive to cost, while the rest had 


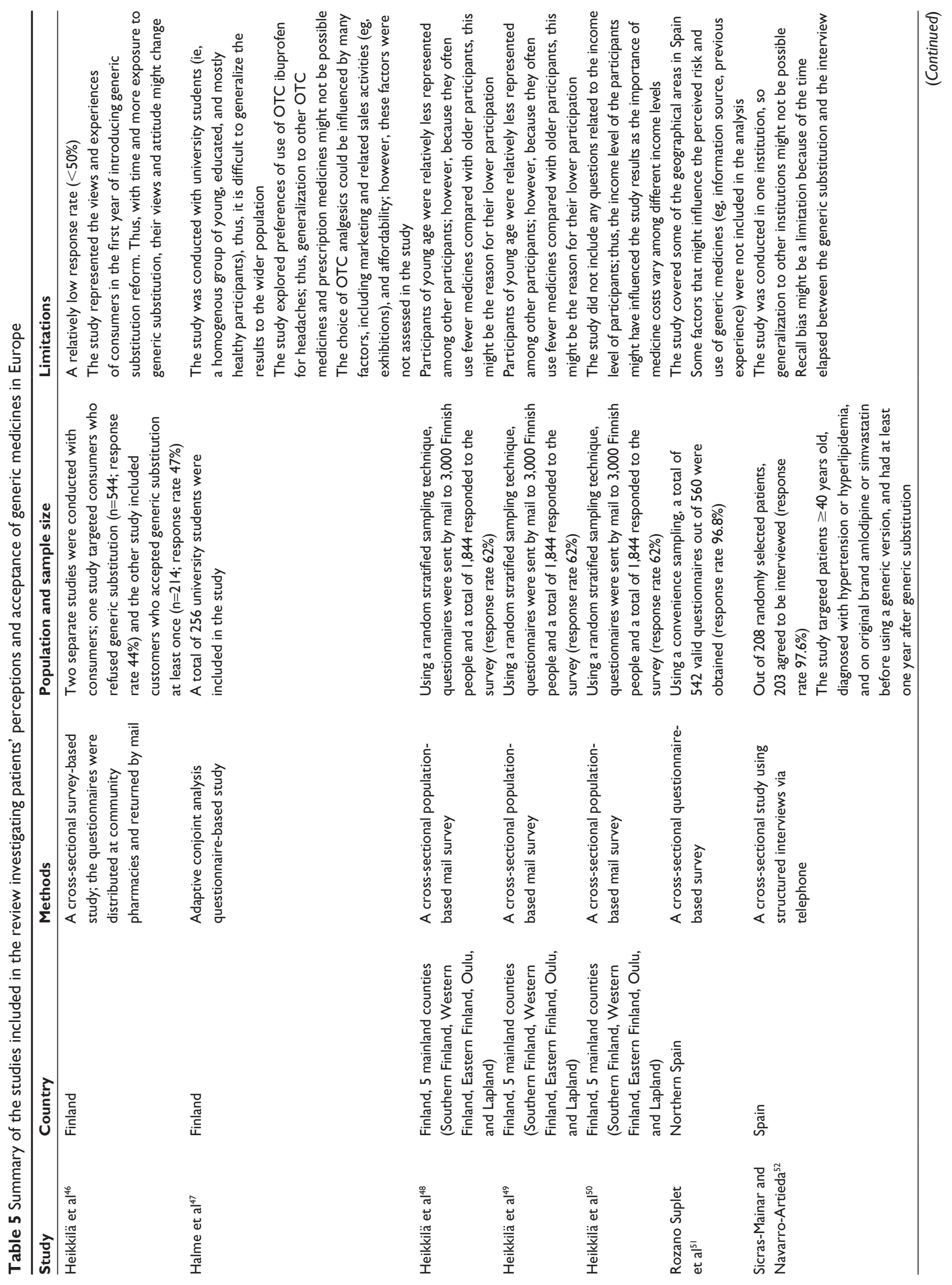



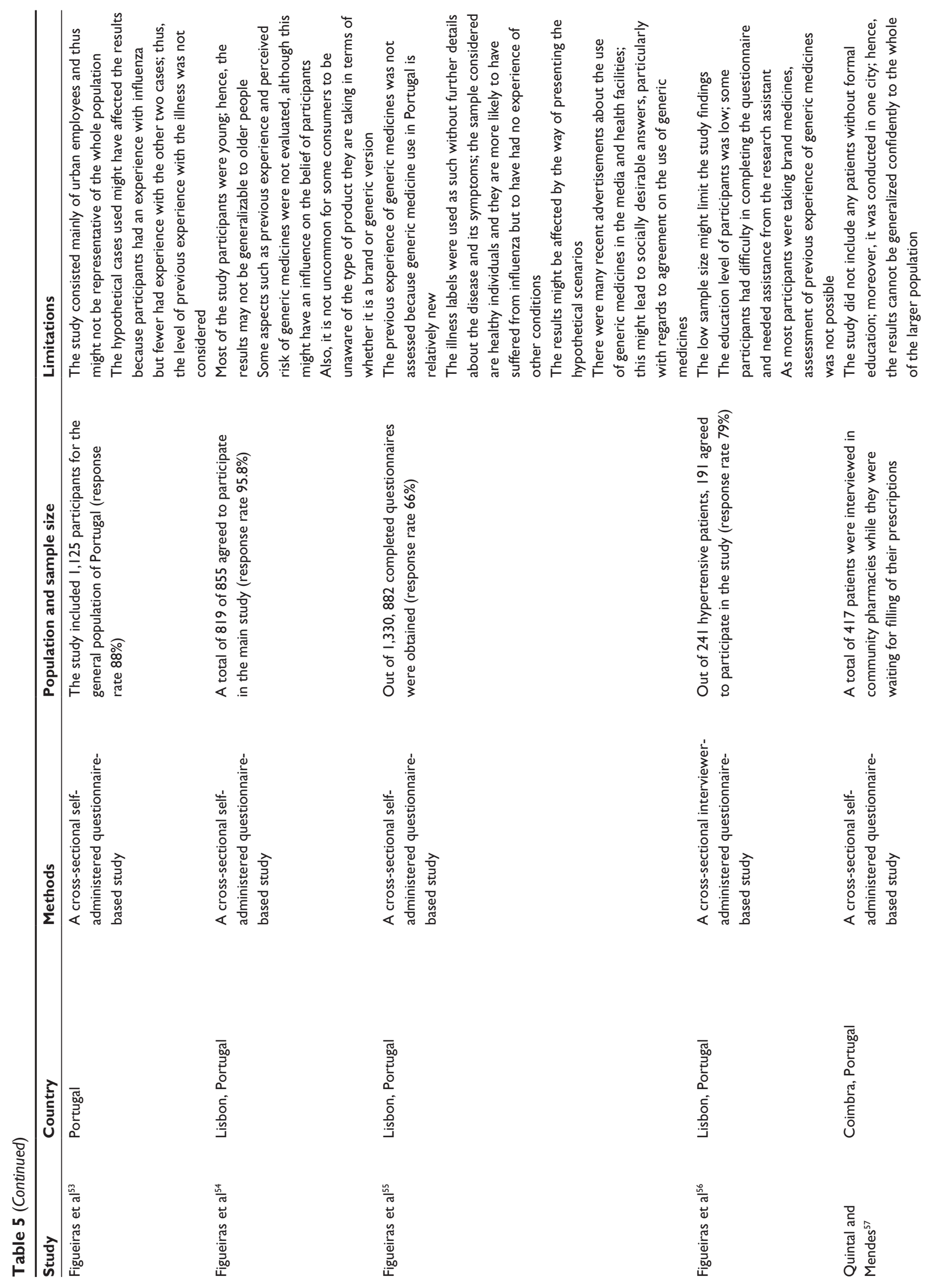

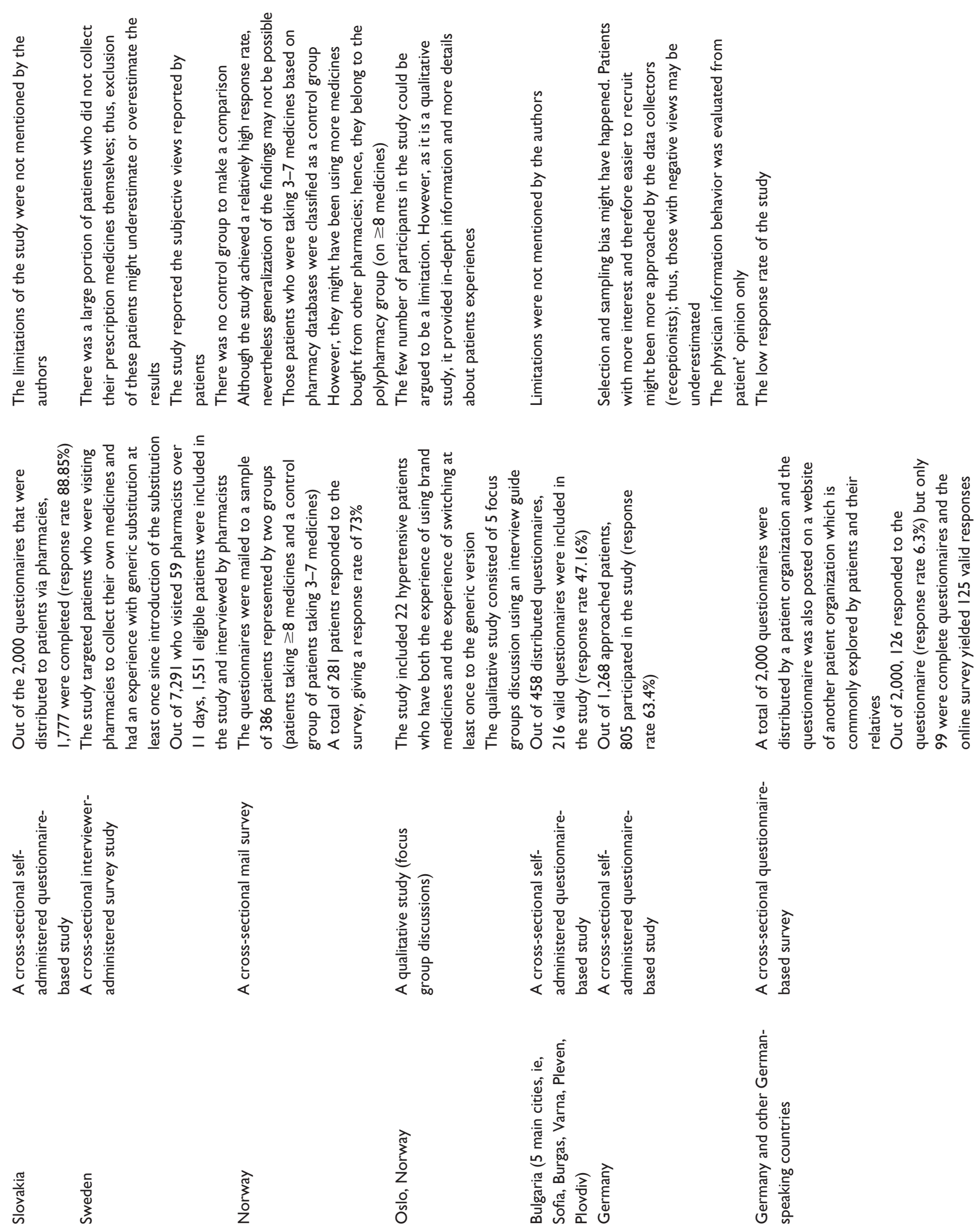

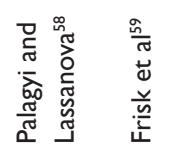

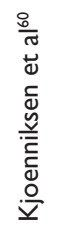

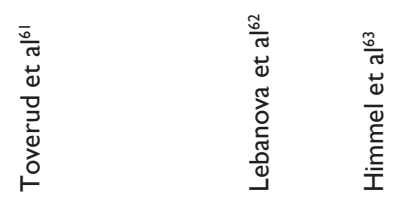

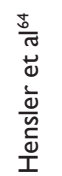




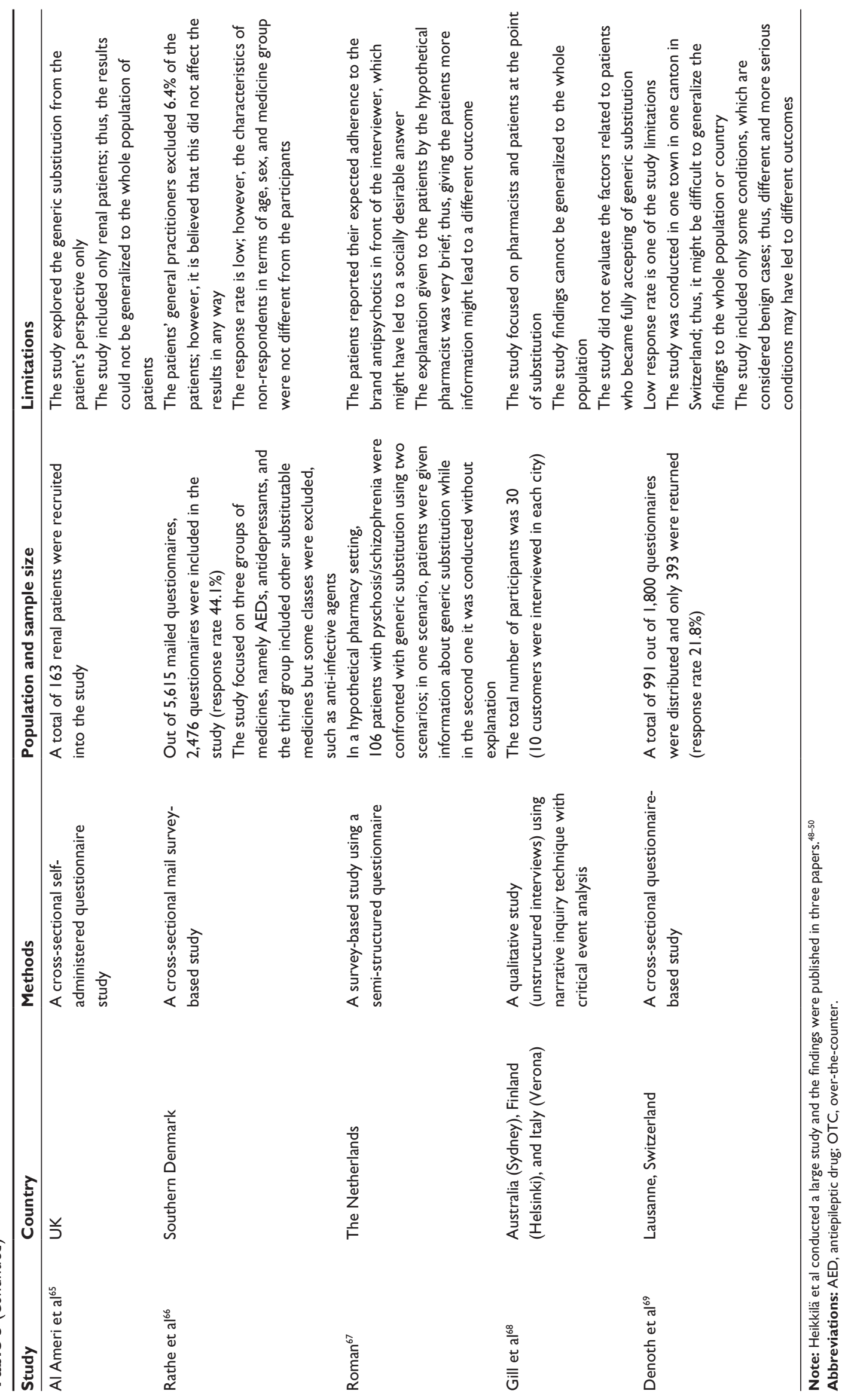


other preferences and considerations when selecting an OTC analgesic, which included brand and advice from a health care professional. The concomitant effect of price, brand, and other factors was an important finding in this study. ${ }^{47}$

Heikkilä et $\mathrm{a}^{48}$ conducted a population-based survey in Finland to study consumers' opinions and attitudes towards generic substitution 5 years after its introduction and to explore perceptions about generic medicines. In this study, $34.3 \%$ allowed generic substitution, $8.6 \%$ refused it, $16.3 \%$ had the experience of both accepting and refusing it, while $40.7 \%$ had no experience of generic substitution. Most respondents (80.9\%) believed that cheaper medicines are effective. In this study, $79.3 \%$ stated that choice of medicine was the domain of their physician. Moreover, $82.4 \%$ were confident that their physician would choose the most suitable product for them. However, $86.2 \%$ stated that they would rely on their pharmacists if they were unsure about the product. The main reasons for accepting generic substitution were cost saving $(65.9 \%)$, recommendation by a pharmacist (65.8\%), and lack of availability of the prescribed brand medicine in the pharmacy (19.6\%). In terms of demographic characteristics and refusing generic substitution, female sex, older age, and use of prescription medicines were associated with refusal of generic substitution. ${ }^{48}$

The same researchers ${ }^{49}$ also explored medicine-related factors that influence a patient's choice of prescription medicines, with special interest in the differences between those who accepted generic substitution and those who refused it. In this study, cost of the medicine (72\%), familiarity with the product (56\%), and product availability ( $42 \%)$ were the three main factors influencing the choice of medicine. Country of origin of the product (25\%), splittability (24\%), excipients used (16\%), manufacturer (10\%), and brand name (8\%) were also reported to influence the choices made by patients, albeit to a lesser extent. However, the study participants did not consider other characteristics, such as color, shape, and packaging design, to be important. Familiarity was the most important factor reported by those who refused generic substitution, while price was the most important factor for those who accepted it (price, $45 \%$ versus $83 \%$, and familiarity, $71 \%$ versus $45 \%$, respectively). ${ }^{49}$

Heikkilä et a ${ }^{50}$ explored the reasons behind patients' refusal of generic substitution. In total, 144 of those who refused generic substitution responded to a question addressing the reasons for refusal (the participants could choose one or more of 13 factors listed for this question). The main reasons were a satisfaction and positive experience with the current product (53\%), agreement with the physician to follow the physician's choice (43\%), and the price difference being too small (19\%). Other reasons included: not being introduced to generic medicines (15\%), wanting to consult their physician before acceptance (14\%), and uncertainty about equivalence due to debate in the media (12\%). The authors concluded that economic factors were not the major factors for the participants' decision to refuse generic substitution. Physicians and health care professionals could play a major role in the promotion of generic medicines and hence help in containing medicine costs. ${ }^{50}$

Rozano Suplet et $\mathrm{al}^{51}$ conducted a survey in northern Spain, to evaluate consumers' perceived risks when using or buying generic medicines in Spain. In this study, the risk dimensions were performance risk, physical risk, social risk, psychological risk, and financial risk, and their relationship with the overall risk of use of generic medicines. The study findings showed that both perceived psychological risk (measured by three statements, "feel uncomfortable purchasing these products", "feel worry caused by doubts about purchasing the product", and "believe it is imprudent to buy generic drugs") and physical risk (measured by the statements "worried about the side effects that the drug can cause in you or a member of your family", "believe that consumption can endanger health", "worried about the possible physical harm that can come from consumption") have a direct and positive effect on the overall perceived risk. In this study, performance, financial, and social risks contributed indirectly to overall risk via the psychological risk. Thus, the perceived psychological and physical risks need to be addressed and patients need to be assured by health care professionals about the safety, quality, and efficacy of generic medicines in order to reduce the perception of risk associated with use of generic medicines. ${ }^{51}$

Sicras-Mainar and Navarro-Artieda ${ }^{52}$ conducted another study in Spain to evaluate patients' opinions regarding the use of generic medicine. The study targeted patients aged $\geq 40$ years and diagnosed with hypertension or hyperlipidemia who had been on the original brands of amlodipine or simvastatin before using the generic version, and it was at least one year since the generic substitution. Of the participants, $47.3 \%$ were taking amlodipine while $52.7 \%$ were on simvastatin. In this study, only $55.3 \%$ reported that they have been provided with adequate information when the generic substitution occurred. While $72.9 \%$ mentioned they had confidence in generic medicines, only $7.3 \%$ stated that they would choose a generic medicine if they could. Regarding their perceptions of generic medicines, $66.8 \%$ reported they are of the same quality while $42.3 \%$ reported that they cause more side effects. 
Interestingly, only $36.1 \%$ indicated generic medicines take the same time to produce the desired effects. Moreover, $61.5 \%$ were more confused by the use of generic medicines. The majority of participants $(81.8 \%)$ reported that they took all the medicines prescribed for them. ${ }^{52}$

Figueiras et $\mathrm{al}^{53}$ conducted a study in Portugal to evaluate the impact of type of disease (influenza, asthma, and angina) on the level of agreement with use of generic medicines. Participants in this study had a relatively positive belief in the efficacy of generic medicines and their similarity to original brand medicines. While there was no association between sex and belief, younger and more educated participants had a more positive belief in the efficacy of generic medicines but a lower belief in their similarity compared with the older participants. The study findings showed that type of disease had a strong influence on level of agreement with use of generic medicines, with acceptance of generic medicines significantly decreasing when the disease was perceived as being more serious (mean agreement score [range: 1 \{strongly disagree\} to 5 s strongly agree\}] $4.07 \pm 0.74$ for influenza, $3.95 \pm 0.86$ for asthma, and $3.89 \pm 0.88$ for angina; $P<0.001$ ). In this study, there was no significant difference between participants in terms of demographic characteristics and level of agreement with use of generic medicines for any of these three illnesses. The authors concluded that there is an association between participants' belief about use of generic medicine and the type of disease they are taking these medicines for. ${ }^{53}$

Figueiras et $\mathrm{al}^{54}$ conducted a study in Lisbon, Portugal, to evaluate the general public's beliefs about generic medicines and also to develop a generic medicines belief scale. Their research consisted of a pilot followed by a main study (here only the results of the main study are presented). The study findings showed that participants had a moderate to strong level of belief in generic medicines but a moderate belief in the similarity of generic medicines with original brand medicines. No statistically significant difference was found between belief in generic medicines and sex. However, older subjects were more likely to have a stronger belief in similarity with the original brand than the younger group (mean score $3.13 \pm 0.61$ for those aged $\geq 24$ years, $3.29 \pm 0.63$ for those aged 25-44 years, 3.39 \pm 0.59 for those aged 45-64 years; $P<0.002$ ). More educated subjects were more likely to have a stronger belief in the efficacy of generic medicine (mean score $3.57 \pm 0.69$ for $\geq 9$ years of education, $3.80 \pm 0.57$ for 12 years of education, and $3.92 \pm 0.54$ for university graduates; $P<0.001) .54$

Figueiras et $\mathrm{al}^{55}$ also conducted a study in Lisbon, Portugal, to determine the influence and relationship between disease type and lay views about the use of generic and brand medicines. The choice of a generic medicine versus a brand medicine was given for four illnesses, ie, influenza, hypertension, asthma, and angina pectoris. A significant interaction was found between type of medicine (generic versus brand) and type of disease, with a higher level of agreement for use of generic medicines for influenza than for angina. Moreover, regarding the efficacy of generic medicines for these different illnesses, the findings showed that belief in the efficacy of generic medicines decreased significantly the more seriously the disease was perceived. Similarly, belief in the ability of generic medicines to relieve symptoms decreased significantly the more seriously the disease was perceived. The authors concluded that their study findings highlight an important point that needs to be taken into account, ie, the association between perception of disease severity and perception of medicines (generic versus brand). ${ }^{55}$

Figueiras et $\mathrm{al}^{56}$ conducted another study, also in Lisbon, to evaluate the perception of illness in patients with hypertension and its association with their belief about medicines and to investigate the relationship between disease schemata (ie, perception of illness) and the choice between brand and generic medicines. This study showed a significant interaction between illness schemata and choice of generic versus brand medicine. Patients with a more negative perception of hypertension (ie, more serious schemata) were more likely to choose a brand medicine, while those with a more positive perception were more likely to choose a generic medicine. Thus, the authors concluded that perception of illness and its seriousness and belief in medicines had an influence on patient preference and choice of generic versus brand medicines for the treatment of their illness. ${ }^{56}$

Quintal and Mendes ${ }^{57}$ conducted a study in Coimbra, Portugal, to evaluate patients' perceptions of generic medicines and their underuse and to explore predictors of experience and willingness to accept generic substitution. All participants knew the term "generic medicines". In this study, $77.5 \%$ of participants had experience of using generic medicines and only $5.8 \%$ indicated that it was a negative experience. In total, $88.7 \%$ and $64.5 \%$, respectively, reported that they were willing to accept generic substitution on the recommendation of physicians and pharmacists. Their main sources of information regarding generic medicines were physicians $(55.6 \%)$, pharmacists $(50.4 \%)$, public campaigns $(27.3 \%)$, health magazines $(16.1 \%)$, and the Internet (14.6\%). There were positive associations between a correct understanding of generic medicines and these 
variables, ie, experience with generic medicines, higher education, and discussion with physicians. According to the patients, the main reasons for low utilization of generic medicines in Portugal are a lack of prescribing by physicians, lack of trust on the part of patients regarding the effectiveness of generic medicines, and no information being received about these medicines. For those who had experience with generic medicines, the main reason for accepting these medicines were recommendation by a physician $(65.3 \%)$ or a pharmacist (19.8\%). Predictors of experience with generic medicines were having a chronic disease, discussion with a physician, and the perception that generic substitution is cheaper for the patient. Predictors of willingness to accept generic medicines based on physician recommendation were correct knowledge, discussion with the physician, experience of generic medicines, and the perception that generic substitution saves patients' money. The authors concluded that patients need to be provided with more information about generic medicines. Thus, health care professionals, ie, physicians and pharmacists, should be encouraged to educate patients about generic medicines rather than focusing their efforts on public education campaigns. Physicians in particular could play a major role in promotion of generic medicines by recommending and prescribing them for their patients. ${ }^{57}$

Palagyi and Lassanova ${ }^{58}$ conducted a study in Slovakia to evaluate patients' attitudes towards generic medicines and to explore their experience of using these medicines. Of the respondents, $33.8 \%$ wanted to know the type of product they were using, ie, whether it was a brand or generic product. Regarding the term "generic medicinal product", $44.4 \%$ described it as "a product with a favorable price", $35.9 \%$ described it as equivalent to the original product, $16.6 \%$ felt it to be a lower quality product, and the rest $(3.1 \%)$ used other descriptions. In this study, 61.1\% had no distrust of using generic medicines. The majority of respondents $(78.6 \%)$ who believed generic medicines are equivalent to original brands had no doubts about using these medicines, while only $21.8 \%$ of those who believed generic medicines to be of lower quality had no doubts about using them. Younger participants (aged $\leq 30$ years) were more likely not to have doubts about generic medicines, and $56.5 \%$ preferred medicines with a lower copayment. However, only a few (15.9\%) of those who had negative beliefs about generic medicines preferred medicines with a lower copayment $(P<0.001)$. The authors concluded that a lack of information about generic medicines could contribute to doubts among patients about their use. Thus, educational interventions for patients are important to dispel any negative beliefs and misconceptions. ${ }^{58}$

Frisk et $\mathrm{al}^{59}$ conducted a cross-sectional study to evaluate patients' experiences with generic substitution 5 years after its implementation in Sweden. Thus, the study targeted patients who were visiting pharmacies to collect their own medicines and had experienced generic substitution at least once since the introduction of the substitution. The study findings showed that $60.2 \%$ did not have any difficulty related to generic substitution, while $39.8 \%$ reported at least one concern or negative experience. The negative experiences reported by participants were that the generic medicines were less effective $(10.6 \%)$, confusion about which medicine/medicines to take $(10.5 \%)$, the side effects of generic medicines (worse or different side effects, $10.3 \%$ ), and medication errors (eg, taking the wrong medicine or taking both the old and the new brand, 6.8\%). Such concerns need to be addressed, and future plans need to consider revising the criteria of generic medicines and brand interchangeability. ${ }^{59}$

Kjoenniksen et $\mathrm{al}^{60}$ conducted a mail survey to evaluate patients' attitudes and experience with generic substitution 3 years after its implementation in Norway. The questionnaires were mailed to a sample of 386 patients representing two groups (ie, patients taking more than eight medicines and a control group taking 3-7 medicines). Twenty-four percent of participants indicated that their physicians had given them information about generic substitution, while a larger proportion (53\%) indicated that the pharmacist had done so. The participants reported that personal monetary/financial savings were a requirement before they accepted generic substitution. However, $27 \%$ reported that they would never accept the offer of generic substitution. Forty-nine percent of participants in this study reported that they had experience of generic substitution, and $64 \%$ of patients on eight medicines or more had experienced a generic switch compared with only $36 \%$ of the control group. Combined information from both physicians and pharmacists resulted in the highest rate of substitution. Regarding patients' experiences of generic substitution, $36 \%$ of those who accepted generic substitution mentioned at least one negative experience. Overall dissatisfaction was stated by $20 \%$, while $18 \%$ felt that generic medicines were of lower efficacy and $12 \%$ reported more side effects compared with the original brand. The authors concluded that about two-thirds of patients who accepted generic substitution were satisfied with the switch. However, there was still a considerable proportion of patients who resisted generic substitution and perceived it as not being equivalent to original brands. ${ }^{60}$ 
Toverud et $\mathrm{al}^{61}$ conducted a qualitative study in Oslo, Norway, to evaluate the attitudes and experiences of generic substitution in patients with hypertension. The study included 22 hypertensive patients who had experienced of using brand medicines and switching at least once to a generic version. The study findings showed that many participants were not taking their medicines as instructed. Most were not aware of what is meant by the term "generic medicine", with only a few stating that a generic medicine is a product that contains the same active ingredient(s) but may have different excipients. Many patients reported that they requested to be given brand medicines to "feel safe" and followed the physician's choice. However, some participants indicated that they would not be reluctant to accept generic medicines if advised to do so by both physicians and pharmacists. Some participants had negative perceptions about generic medicines in terms of their quality, efficacy, and safety. Many patients felt that pharmacists were too active in offering generic substitution. Thus, some patients felt uncomfortable, especially those who did not want to switch to generic medicines, while many thought that pharmacists were too keen to sell their own cheap medicines. Therefore, in this study, patients hoped that physicians would play a more active role in telling them about generic medicines and generic substitution. ${ }^{61}$

Lebanova et al ${ }^{62}$ conducted a study in Bulgaria to evaluate patients' attitudes and knowledge of generic medicines. In this study, only $11 \%$ reported that they knew the difference between generic brand name medicines, while $46 \%$ did not know and $43 \%$ were not sure about the differences. Moreover, only one-third of participants with chronic disease knew the difference between generic and brand medicines. In this study, almost all participants, including those with chronic disease (94\%), preferred original brand medicines over generic medicines. Most participants (79.6\%) reported that they were mostly prescribed original brands by their physicians. Moreover, according to the authors, given that generic substitution by pharmacists is not allowed in Bulgaria, physicians play an essential role in this process. Also, lack of knowledge or insufficient information about generic medicines had a great influence on patients' acceptance of and preference for generic medicines. ${ }^{62}$

Himmel et al ${ }^{63}$ conducted a study in Germany to evaluate patients' attitudes towards generic medicines. In this study, $63 \%$ of participants felt that they were aware of the difference between generic and brand medicines, and had been informed of the difference via the media (65\%) and/or via their physician (52\%). Patients with 10 or more years of education were more likely to know the differences than those with less education ( $74.6 \%$ versus $51.8 \%$, respectively). In this study, $36.7 \%$ of patients believed that inexpensive medicines are inferior to brand medicines. Older patients had a more negative attitude towards generic medicines, while those with a higher level of education and those with experience of generic medicines/generic substitution had a more positive attitude. Also, $50.5 \%(\mathrm{n}=112)$ of those who could remember being offered a generic substitution stated that they had been skeptical about it. Among those who had experienced generic substitution $(\mathrm{n}=222)$, approximately $30 \%$ were not satisfied with the information provided to them about generic medicines by their physicians; $13.2 \%$ reported more side effects, and $12.2 \%$ pointed out that their generic product was less effective than the brand medicine. This study highlighted a significant association between skepticism concerning generic substitution and not being well informed about the substitution, and also a strong association with the perception that cheaper medicines are inferior to brand products. ${ }^{63}$

Hensler et a ${ }^{64}$ conducted a survey in Germany and other German-speaking countries to investigate patients' attitudes towards generic substitution of AEDs. The respondents indicated that the effectiveness of their AEDs was their main consideration when selecting AEDs. They were more resistant to the use of generic AEDs, but were neutral towards use of generic medicines for other acute and short-term medical conditions. In this study, $61 \%$ preferred not to use generic medicines for epilepsy even if it would save costs, and $77 \%$ reported that cost should not be an important factor when selecting therapy for epilepsy. In this study, $70 \%$ of participants felt that they would be uncomfortable not receiving the specific product prescribed by their physician. ${ }^{64}$

Al Ameri et al ${ }^{65}$ conducted a study in the UK to canvass the opinions of renal patients on generic substitution. Seventy percent of participants reported that they knew the terms "generic medicines" and "brand medicines", and $54 \%$ indicated that they were aware of generic substitution. The vast majority of participants $(84 \%)$ thought that generic medicines are not equivalent or are only sometimes equivalent or were unsure about their equivalency and quality compared with brand medicines. Most patients who were taking generic medicines were dissatisfied $(14 \%, n=8)$ or not sure about their satisfaction $(53 \%, n=29)$. More than half $(55 \%)$ were concerned that use of generic medicines may negatively influence their adherence to medication. Irrespective of their renal transplant, 55\% reported that they would accept generic medicines in the case of mild illness, while only $34 \%$ would accept these medicines in the case 
of chronic conditions. Among those who responded to the question related to provision of information about generic medicines, 79\% $(n=53)$ stated that no information about generic medicines or substitution had been provided to them. Only $19 \%$ were aware of the availability of generic cyclosporine and only $23 \%$ reported that they would agree to accept a generic substitution of their brand of cyclosporine. The authors concluded that many renal patients had doubts about generic medicines. Thus, education and reassurance are important in promoting the use of generic medicines and to enhance patient acceptance. ${ }^{65}$

Rathe et $\mathrm{al}^{66}$ conducted a study in Southern Denmark to evaluate the association between generic switching or substitution and patients' beliefs, attitudes, and experiences. Their study focused on three groups of medicines, namely AEDs, antidepressants, and a third group which included some other substitutable medicines. The percentages of patients who had experienced a generic substitution comprised $35.3 \%, 26 \%$, and $32.6 \%$ for the antidepressant group, AED group, and other substitutable group, respectively. The study findings showed that previous experience of generic switches within the index Anatomical Therapeutic Chemical (ATC) $\operatorname{code}^{66}$ and younger age group were significantly associated with the experience of generic substitution. Conversely, having more than five substitutions in other ATC codes and negative views about generic medicines were negatively associated with the experience of generic substitution. However, there were no significant associations between generic substitution and medicine group, number of medicines the patients were taking, and their general belief about generic medicines. ${ }^{66}$

Roman ${ }^{67}$ conducted a study in the Netherlands to evaluate the attitudes of psychiatric patients (with psychosis/ schizophrenia) towards generic substitution of oral atypical antipsychotic agents. In a hypothetical pharmacy setting, 106 patients with psychosis/schizophrenia were confronted with generic substitution using two scenarios. In one scenario, patients were given information about generic substitution while in the second one generic substitution was done without explanation. In this study, $73 \%$ of patients reported that they would be unlikely to accept generic substitutions for their antipsychotic medicines if offered them by pharmacists. Previous experience of switching their antipsychotic medicines or of generic substitution at the pharmacy was not associated with intention to use generic versions. The vast majority of respondents $(86 \%)$ preferred their current antipsychotic brand medication and only $4 \%$ preferred the generic version while the rest (10\%) were neutral. The major reasons given were familiarity with the current brand (73\%), that it had been prescribed by the psychiatrist (23\%), and a belief that it would give a better outcome ( $8 \%$ ). In this study, the vast majority $(87 \%)$ refused generic substitution. The main reasons behind this were its different packaging (50\%), no belief in its effectiveness because it was not recommended by their psychiatrist (28\%), and 10\% believed that the pharmacist might have made a mistake as the medicine looks different. In this study, 52\% reported that they would consult their psychiatrist before accepting a generic version. Overall, based on differences in physical and external appearance, the psychiatric patients in this study considered the generic versions of their brand antipsychotic medicines as being "different medicines" from the brand versions, even after it was explained that they have the same active constituent. ${ }^{67}$

Gill et a ${ }^{68}$ conducted a qualitative study to explore customers' experiences with generic substitution in Sydney, Australia, in Helsinki, Finland, and in Verona, Italy. The study showed that unawareness of substitution was common, especially when customers or patients were offered generic substitution for the first time. As a result, patients were confused and suspicious of it. However, some patients, although aware of the general concept, were reluctant to accept the generic substitution, avoiding introduction of something new into their life. Moreover, when customers were confronted with generic substitution, they were confused as to why they were being offered something that seemed to be different to what had been prescribed by their physician. Thus, as a reaction to the situation, they wanted to be sure of the quality and efficacy of the generic version. Further, in Finland and Italy, even those who accepted generic substitution still wanted to consult their physician regarding the generic medicine. Moreover, because customers trusted their physicians, they were skeptical as to why the pharmacist was offering the generic substitution. Most of them thought the motive behind the pharmacist's offer was financial benefit. In Australia, the customers interviewed felt that financial benefit was behind the behavior of both physicians and pharmacists. In general, many participants in this study had misconceptions about generic medicines and manufacturers of generic products. ${ }^{68}$

Denoth et $\mathrm{l}^{69}$ conducted a study in Lausanne, Switzerland, to determine the preference of participants for generic medicines and brand name medicines for the treatment of acute and chronic illnesses. To achieve their objective, the study assessed preference by willingness to pay for brand medicines in eight hypothetical scenarios, namely acute bronchitis (scenario 1); a twisted ankle (scenario 2); heartburn (scenario 3); an acute urinary infection (scenario 4); hypertension (scenario 5); 
knee arthritis (scenario 6); non-steroidal anti-inflammatory drug-induced heartburn (scenario 7); and hypercholesterolemia (scenario 8). For the eight scenarios, 65.1\%-70.5\% of participants stated that they were not willing to pay for brand medicines rather than the generic versions (willingness to pay, 0). Participants with disease (acute or chronic) were willing to pay more for brand medicines than participants in good health. This difference was statistically significant for all the scenarios involving participants with acute illness, but only so for four of the scenarios involving participants with chronic illness. Moreover, participants with chronic disease showed a significantly higher willingness to pay than those without chronic disease for three of the four scenarios involving chronic conditions. Overall, this study showed that many participants believed there was no additional value in using brand medicines. ${ }^{69}$

\section{Studies from Africa, Latin America, and the Caribbean region}

There were three studies identified from these regions. One study was from Jamaica (Caribbean region), one was from South Africa, and one was from Brazil. A summary of the characteristics of these studies is presented in Table 6. Gossell-Williams and Harriott ${ }^{70}$ conducted a survey in Jamaica to evaluate patients' knowledge of generic medicines and their sources of information. Most patients (63.6\%) were not familiar with the term "generic medicine" or its meaning. Even among those who were familiar with generic medicines, many described them as a cheaper brand rather than a cheaper, equally effective alternative brand. Among those who knew of generic medicines, physicians $(n=288)$ and pharmacists $(n=35)$ were the major sources of medicine information. There was no association between acceptance of generic substitution and income, medical insurance coverage, or drug adherence. Most patients reported that they would follow their physician's prescription whether a brand medicine or a generic medicine, and would not request a generic substitution at the pharmacy because they considered that their physician knows best. The authors concluded that patient acceptance of generic medicines is determined by physicians' confidence in generic medicines and willingness to prescribe them.

Patel et $\mathrm{al}^{71}$ conducted a qualitative study in South Africa to explore consumers' knowledge of the quality of medicines and whether they used generic medicines. In this study, participants lacked knowledge about generic medicines and perceived them as being of poor quality, with some participants even describing them as "fake" medicines, mainly because of their cheaper price or because they are given freely at government health facilities. The major facilitator of generic acceptance was a recommendation and prescription by the physician. However, recommendation by the pharmacist or drug dispenser played a minor role in acceptance of generic substitution. ${ }^{71}$

Bertoldi et $\mathrm{al}^{72}$ conducted a survey in Pelotas, Southern Brazil, to explore consumers' knowledge and use of generic medicines. An inspection of the medicines used and available in participants' homes revealed that $51.2 \%$ were brand medicines, $25.6 \%$ were similar medicines, $18.0 \%$ were formulated medicines, $3.9 \%$ were generic medicines, and natural or homeopathic products accounted for $1.3 \%$. Brand medicines were more likely to be used by younger, wealthier, and more educated participants. However, generic medicines were rarely used, and there was no significant association between use of generic medicine and sociodemographic characteristics. The vast majority $(86.0 \%)$ of participants stated that generic medicines are less expensive than brand medicines, and $70.0 \%$ stated

Table 6 Summary of studies included in the review investigating patients' perceptions and acceptance of generic medicines in Africa, Latin America, and Caribbean region

\begin{tabular}{|c|c|c|c|c|}
\hline Study & Country & Methods & Population and sample size & Limitations \\
\hline Bertoldi et $\mathrm{al}^{72}$ & $\begin{array}{l}\text { Pelotas, Southern } \\
\text { Brazil }\end{array}$ & $\begin{array}{l}\text { Cross-sectional population-based } \\
\text { survey using an interviewer- } \\
\text { administered questionnaire }\end{array}$ & $\begin{array}{l}\text { A total of } 3,182 \text { out of } 3,372 \text { eligible } \\
\text { individuals who were found in } \\
\text { I,600 sampled households agreed } \\
\text { to participate in the study (response } \\
\text { rate } 94.4 \% \text { ) }\end{array}$ & $\begin{array}{l}\text { The limitations were not } \\
\text { mentioned by the authors }\end{array}$ \\
\hline $\begin{array}{l}\text { Gossell-Williams } \\
\text { and Harriott }{ }^{70}\end{array}$ & Jamaica & Questionnaire-based survey & $\begin{array}{l}\text { Total of } 1,020 \text { patients participated } \\
\text { in the study (response rate } 99.1 \% \text { ) } \\
\text { General population }\end{array}$ & $\begin{array}{l}\text { The limitations were not } \\
\text { mentioned by authors }\end{array}$ \\
\hline Patel et all1 & $\begin{array}{l}\text { South Africa, (Durban, } \\
\text { Cape Town, and } \\
\text { Johannesburg) }\end{array}$ & $\begin{array}{l}\text { Qualitative study using focus } \\
\text { group discussions }\end{array}$ & $\begin{array}{l}\text { Study consisted of } 12 \text { focus group } \\
\text { discussions and included a total } \\
73 \text { participants } \\
\text { General consumers }\end{array}$ & $\begin{array}{l}\text { The limitations were not } \\
\text { mentioned by authors }\end{array}$ \\
\hline
\end{tabular}


that generic medicines are of the same quality as brand medicines. In this study, $56.6 \%$ were able to identify some of the features and characteristics of generic medicines in comparison with other medicines. Overall, $42 \%$ gave correct responses to all three questions about generic medicines. Sixty-three percent of the individuals surveyed reported that they generally used prescription medicines exactly as written by their physicians and did not substitute them with generic equivalents. In this study, the price of the medicine and medical prescribing were the main factors determining the use of medicines. The authors concluded that generic medicines in Brazil, although known of by many, are used by only a few. Thus, the authors recommended that health care professionals, particularly physicians, should encourage the use of generic medicines by prescribing them more often to their patients. ${ }^{72}$

\section{Discussion}

\section{Understanding the term "generic medicine"}

In many studies conducted in different countries, the term "generic medicine" is not commonly used by medicine consumers or patients, and most are either not familiar with the term or have never heard it. ${ }^{30,34-36,39,41,70}$ For example, only $51.6 \%, 68.4 \%, 32.5 \%, 36.4 \%$, and $28.3 \%$ of participants in New Zealand, Japan, Malaysia (Kuala Lumpur and Selangor), Jamaica, and Malaysia (Penang), respectively, were familiar with the term or had heard of it. ${ }^{34-36,39,70}$ On the other hand, in a few countries, such as Portugal, all patients $(100 \%)$ knew the term "generic medicine" and were familiar with its meaning. ${ }^{57}$ Similarly, in the UK, a high percentage of participants $(70 \%)$ felt that they understood the terms "brand medicine" and "generic medicine". However, in practice, most of them (75\%) were not aware whether the medicines they were taking were generic medicines or brand medicines. Therefore, understanding or familiarity with the term does not necessarily mean that the consumers can differentiate between brand and generic medicines. ${ }^{65}$

In fact, this issue, ie, the terminology used by patients and consumers to describe generic medicines, is widely discussed in the literature. For example, in Iraq (an Arabic-speaking country), Adheed and Hassali reported that medicine consumers used the term "Tejari" (commercial) medicine to describe generic medicines, while they used "Asli" (original) to describe brand medicines. ${ }^{41}$ In Alabama, USA, patients defined and described brand medicines as "the real thing", "real drugs", "real medicine", and "regular medicines", but described generic medicines as the opposite of these terms, eg, "not real medicines" or "off brand from the real thing". ${ }^{27}$ Further, in the study conducted by Thomas and Vitry in Kuala Lumpur and Selangor, Malaysia, participants described generic medicines as cheaper brands (51\%), non-original and non-genuine (18\%), or local medicine or a medicine made by a different company (18\%), and few (13\%) described it as "a different brand of medicine with the same content". ${ }^{36}$ In Australia, almost all medicine consumers interviewed referred to generic medicines with the term "cheaper brand". ${ }^{30}$

\section{Understanding the concept of generic medicine}

Understanding of the technical definition of generic medicine (ie, a medicine that contains the same active ingredient(s) and the same dose as the original brand but may contain different excipients and be marketed under a different trade name by a different company) was explored in many studies. A number of studies conducted across several countries, including Japan, New Zealand, Bulgaria, Iraq, Malaysia, and Norway, explored medicine consumers' understanding of the differences between generic medicines and brand medicines, and many reported a lack of knowledge among a high proportion of participants. ${ }^{34,36,38,39,41,61,62}$ For example, in Japan, only $71.1 \%$ stated that generic medicines and brand medicines have the same active ingredients. The majority $(53.7 \%)$ of patients had no idea whether the inactive ingredients are the same or not, while $12.5 \%$ wrongly believed they are the same..$^{39}$ In Norway, most of the respondents were not aware what a generic medicine is and how it differs from the brand medicine, with only a few participants being aware that it is the same medicine (ie, the same active ingredient but possibly different excipients). ${ }^{61}$ In Bulgaria, most participants were either in the "do not know" (46\%) or "not sure" (43\%) category when asked about the difference between brand and generic medicines. Further, nearly $75 \%$ of patients with chronic disease do not have enough information about the difference between generic and original medicines. ${ }^{62}$ Similarly, in Iraq, most patients were not aware of the differences between brand and generic medicines in terms of their active ingredients. ${ }^{41}$ Similarly, in Malaysia, when defining generic medicine, only $13 \%$ selected the option "a different brand of medicine with the same content". ${ }^{36}$ On the other hand, in the UK study, $84 \%$ of participants reported that they are aware of the availability of different brands (ie, versions) of the "same medicine", ${ }^{65}$ and almost the same percentage (78.2\%) in Portugal claimed to be informed about generic medicines. $^{57}$ 


\section{Preferences and perceptions of generic medicines}

Many studies in the literature show that medicine consumers prefer original brand medicines rather than generic versions. . $12,23,26,27,38,62,72$ In Japan, only $17 \%$ of study participants mentioned having used generic medicines, despite the fact that the vast majority (86.7\%) knew about their availability. ${ }^{38}$ In Brazil, the situation described by Bertoldi et al is that generic medicines are "known by many but used by few". ${ }^{72}$ In Tennessee, USA, most patients were aware of the value and benefits of generic medicines as being less expensive medicines and with safety and efficacy profiles comparable with those of the original brand medicines. However, such awareness did not translate into a preference for generic medicines, given that only $45.3 \%$ would take generic medicines instead of the original brand medicines. The authors summarize the situation and patients views as "generic medications for you, but brand-name medications for me". ${ }^{26}$ A similar finding was reported by Shrank et al, ie, "although most Americans appreciate the cost-saving value of generics, few are eager to use generics themselves". ${ }^{23}$ Further similar findings were reported by Sewell et al in Alabama, USA, where most participants indicated that they would use brand medicines rather than generic medicines if they could afford their cost. ${ }^{27}$ In Bulgaria, almost all participants (94\%), including those with chronic diseases, preferred original brand medicines over generic medicines. ${ }^{62}$ In Australia, only $29.7 \%$ of study participants agreed that they would take generic medicines rather than brand medicines. ${ }^{32}$

A large body of literature has reported misconceptions and negative perceptions about generic medicines among patients and medicine consumers. However, although this is reported in almost all countries, the percentage of consumers with such misconceptions can vary widely from one country to another. ${ }^{21,23,27,30,33-35,38,44,46,52,59,62,65,71-73}$ For example, in Malaysia, many participants reported that generic medicines are of lower quality (38.9\%), are less effective (34.8\%), and produce more side effects (31.2\%). ${ }^{35}$ In Alabama, USA, many of the participants interviewed in the qualitative study conducted by Sewell et al believed that generic medicines are less effective, less potent, and might produce more side effects. Thus, most of them were hesitant to use generic medicines and would use original brands or "the best medicines", as they described them, whenever they could afford them. ${ }^{27}$ In Spain, only $66.8 \%$ of participants considered generic medicines to be of the same quality as brand medicines, while $42.3 \%$ agreed that generic medicines produce more side effects and only a few (36.1\%) agreed that generic medicines take the same time to produce their therapeutic effects. ${ }^{52}$ In the USA, almost $30 \%$ agreed that original medicines are more effective than their equivalent generic versions, and less than $10 \%$ felt generic medicines to be less safe than the original brands. Nevertheless, only $37.6 \%$ reported that they would rather take generic medicines than brand medicines. ${ }^{23} \mathrm{In}$ Bulgaria, almost $94 \%$ believed that generic medicines are inferior in terms of quality, safety, and efficacy compared with brand medicines. ${ }^{62}$

The studies that focused on specific populations, eg, patients with epilepsy, psychosis, or renal disease, reported a more negative perception and more resistance to use of generic medicines. ${ }^{33,44,65,67}$ For example, in Australia, about $80 \%$ of patients felt more comfortable asking their doctors for only original brands of their AEDs and 68\% were not comfortable being treated with generic medicines for their epilepsy. Most participants expressed concerns about the efficacy (70.2\%) and safety (55.4\%) of generic AEDs. Cost savings would encourage only $23.4 \%$ to use generic AEDs. ${ }^{33}$ In the study of renal transplant patients in the UK, about $84 \%$ of patients believed that generic medicines are not equivalent to the original brands and were not sure about the quality of generic medicines. When participants were asked about a specific immunosuppressant agent (ciclosporin), only $23 \%$ stated that they would accept the offer of generic substitution when its generic version becomes available. ${ }^{65}$

Correct knowledge and understanding of generic medicines as being clinically interchangeable and with the same efficacy, safety, and quality as the original brand medicines are important factors for acceptance and increased use of generic medicines. Misconceptions and negative perceptions are reported to be major obstacles to use and acceptance of generic medicines by patients. ${ }^{27,30,38,46,59,73}$ For instance, in Finland, there was a difference between those patients who accepted generic substitution and those who refused it in terms of their disagreement with the statement that generic medicines are not safe ( $77 \%$ versus $63 \%$, respectively), and also a difference between their agreement with the statement that generic medicines are effective (66\% versus $43 \%){ }^{46}$

\section{Use of generic medicines for mild, serious, and chronic diseases}

The type of medical condition and its level of severity were considered to be important factors affecting the decision whether to use a generic medicine or brand medicine. Patient acceptance of generic medicines according to type of medical condition has been addressed and widely discussed in many studies reported in the literature. ${ }^{20,26,27,35,44,53,55,56,65,69,73,74}$ For example, in the study 
conducted in Alabama, USA, medicine consumers reported being unwilling or hesitant to accept generic medicines for serious diseases, eg, hypertension and cancer, but were willing to use them for minor illnesses, eg, allergies and colds. ${ }^{27}$ In the study conducted in the UK, the severity of the medical condition was reported as being a factor influencing the choice to use generic medicines, with $55 \%$ of participants being willing to accept generic substitution for a mild illness but only $34 \%$ being willing to accept generic medicines for a chronic disease. ${ }^{65}$ In Malaysia, Al-Gedadi et al reported that medicine consumers were more willing to use generic medicines for mild conditions (eg, headache, fever, and influenza) but were less likely to use them for more serious diseases, such as diabetes. In that study, $78.3 \%$ indicated they would use generic medicines for mild conditions, but only $1.5 \%$ would do so for serious conditions. ${ }^{35}$

Moreover, in Portugal, Figueiras et al investigated the impact of type of disease (influenza, asthma, angina) on the level of agreement with use of generic medicines. They showed that type of disease has a significant effect on the level of agreement with use of generic medicines, with acceptance of generic medicines decreasing significantly when the disease is perceived as being more serious (mean score $4.07 \pm 0.74$ for influenza, 3.95 \pm 0.86 for asthma, and 3.89 \pm 0.88 for angina; $P<0.001) .{ }^{53}$ Figueiras et al also studied the influence of views and perceptions concerning generic medicines and their association with use of these medicines for different diseases, specifically influenza, asthma, hypertension, and angina, and found an interaction between type of disease and type of medicine selected (ie, brand versus generic medicine). The more serious the disease was perceived to be, the lower the belief in using generic medicines for treatment. ${ }^{55}$ In a further study, Figueiras et al investigated the perception of illness in patients with hypertension and its association with their beliefs concerning generic versus brand medicines. They found a significant interaction between illness schemata (ie, perception of illness) and choice of generic versus brand medicines. Patients with a more negative perception about hypertension (ie, more serious schemata) were more likely to choose a brand medicine, while those with a more positive perception were more likely to choose a generic medicine. ${ }^{56}$ In short, the seriousness of the medical condition is an influencing factor, and the more serious or risky the patient perceives the condition to be, the less likely they are to use a generic medicine..$^{53,73,74}$

\section{Role of health care professionals in use of generic medicines}

There is strong evidence in the literature that both physicians and pharmacists play an essential role in the promotion of generic medicines and patients' acceptance of their use and generic substitution. ${ }^{30,34,35,39,41,46,48,57,60}$ In Spain, the vast majority of medicine consumers $(81.8 \%)$ surveyed would take generic medicines if prescribed by their physicians. ${ }^{52}$ In New Zealand, the majority of medicine consumers would accept generic medicines based on a pharmacist's recommendations for both mild conditions (78\%) and serious conditions (58.7\%). ${ }^{34}$ In Malaysia, over $75 \%$ of those surveyed indicated that they would use generic medicine on the recommendation of a physician or pharmacists. ${ }^{35}$ In Norway, information and advice given to patients by physicians and pharmacists was an influential factor in their use of generic medicines. This study found that $84 \%$ of those who switched to generic medicines had received information, while only $27 \%$ of those who did not switch had received information. ${ }^{60}$ In Japan, the main facilitator of acceptance of generic substitution was the recommendation of a physician or pharmacist. ${ }^{39}$ In Finland, recommendation at the pharmacy was the reason for accepting generic medicines and substitution according to $65 \%-72 \%$ of patients. ${ }^{46,48}$ Further, in some countries, it seems that physicians have a relatively more influential role than pharmacists in convincing patients to use generic medicines. For instance, in Portugal, 88.7\% would accept generic substitution based on their physician's recommendation but only $64.5 \%$ would do so on a pharmacist's recommendation. ${ }^{57}$ In Japan, the main reasons for accepting generic medicines were the physician's recommendation $(48.6 \%)$ and, to a lesser extent, the pharmacist's recommendation (33.1\%). ${ }^{39}$ In the UK, 75.3\%, 33.3\%, 24.8\%, and $20.8 \%$ of patients reported that they would accept generic substitution if initiated by a medical consultant/hospital doctor, general practitioner, pharmacist, or nurse, respectively. ${ }^{65}$ However, just as health care professionals can enhance use of generic medicine, they can also decrease it by prescribing, dispensing, or recommending only brand medicines. As a result, their inclination or preference for brand medicines can influence their patients' choice of medicines and hence could be a barrier to use of generic medicines. ${ }^{30,34,38,41,46,50}$ For example, in one study, lack of prescribing of generic medicines by physicians was the main reason cited for patients not using them. ${ }^{38}$ In New Zealand, the top reason given for not changing a brand of medicine was the recommendation of physicians and pharmacists. ${ }^{34}$

\section{Lack of information about generic medicines among patients}

Most studies reported in the literature cite a lack of knowledge or unawareness or insufficient information about generic 
medicines among many medicine consumers. ${ }^{30,34,36,41,44,57,62,65}$ The level of knowledge about generic medicines is an important factor for acceptance and use of generic medicines because insufficient information about generic medicines is one of the main barriers to the wider use of these medicines. ${ }^{30,34,41,57,62,73}$

\section{Implications for practice, policy, and future research}

Patients' knowledge of generic medicines and generic substitution is a prerequisite for better use and acceptance of generic medicines. However, most studies reflect a lack of adequate information about generic medicines among patients and medicine consumers. Therefore, it is important to empower patients with adequate information. Health authorities need to promote generic medicines via educational interventions and educational campaigns in hospitals, clinics, community pharmacies, and shopping malls, and also via the mass media, including television programs. Such initiatives could help to raise the level of awareness of the availability and value of generic medicines.

It is evident in the literature that direct education and advice from health care professionals about use of generic medicines is very effective, not only to persuade patients accept to generic medicines, but also to make them confident and feel more comfortable about using these medicines. Therefore, physicians need to actively inform their patients about generic medicines, and pharmacists also need to educate patients about these medicines. Therefore, health authorities need to consider this point and encourage health care professionals to play active roles in this regard. Further, as the role of health care professionals is highly influential, it is essential to ensure that they have adequate knowledge and information sources about generic medicines so that they can perform their role efficiently.

Communication and coordination between physicians and community pharmacists about generic substitution is essential to prevent confusion, doubt, and concern among patients about the process of generic substitution given that patients are often faced with a situation in which the physician is prescribing "something" and the pharmacist is offering "another thing". Such a situation makes some patients feel not only doubtful and reluctant to accept a generic medicine, but also psychologically uncomfortable even after accepting the generic medicine, which could influence their adherence with medication. Therefore, in countries where generic substitution is common practice, physicians need to be encouraged to prescribe generically or to inform patients about generic substitution in the clinic, so that they will not be surprised or confused by the pharmacist's offer of generic substitution. In countries where generic substitution is not common practice, physicians need to prescribe more generic medicines for their patients, because it is evident in the literature that patients usually follow their physician's choice and hence refuse the offer of generic substitution at the pharmacy in most cases.

Educational interventions need to cover all aspects of generic medicines, including their availability, equivalence with original brands in terms of active ingredient, quality, safety, effectiveness, and bioequivalence. It is also important to educate patients regarding the regulatory approval and registration system for medicines in their country and to assure them that all medicines, including generic medicines, undergo the same rigorous process. Also, some myths about generic medicines, eg, lower price equates to lower quality, need to be refuted.

It is evident from the literature that the price difference between generic medicines and brand medicines is a major factor that influences patients' choice. When the price difference between brand medicine and generic medicine or the amount that patients pay to get the original brand is minimal, patients prefer to use the original brand. Thus, a differential copayment system plays an important role. This system, which is applied in some countries, requires patients to pay an additional or higher copayment when they refuse a generic medicine. Therefore, in addition to knowledge and awareness, this point is an important one to be considered by health authorities and health policy makers.

It is also clear in the literature that some patient groups (eg, those with epilepsy) are relatively more resistant to acceptance of generic medicines. Patients with chronic diseases are also relatively more reluctant to accept generic medicines than patients with acute conditions. This is an important barrier that needs to be considered by health policy makers and health care professionals, and more effort needs to be made to educate these groups of patients, given it is these patients who need to take medicines for a long period of time, where use of generic medicines will enable substantial cost savings.

It is evident in the literature that lack of knowledge and awareness of generic medicines is not only a barrier to acceptance of generic medicines but could also have negative consequences, such as non-adherence with therapy, confusion due to difference in color, shape, and trade name, and potential medication errors.

There is a paucity of information concerning the ideal or optimum structure and content of educational interventions targeting patients about generic medicines, and currently 
there are no evidence-based data in the literature about the effectiveness of such interventions. Thus, it is important to identify the most suitable educational interventional programs and also to conduct studies evaluating the impact of such interventions on patients' knowledge and acceptance of generic medicines.

\section{Limitations}

The review adds to the existing information on the perceptions of patients or consumers regarding generic medicines. Nevertheless, it has some limitations. First, it focuses more on the recent literature, ie, from 1990 and onwards. However, this is justified because older studies might not be relevant to current practices. Perceptions and views do change over time, and a large number of generic medicines have been marketed in the last two decades. Thus, more patients and consumers are exposed to generic medicines. Many initiatives, policies, and promotion programs have been introduced in recent years, which might have an effect on patients' perceptions and views. Also, information technology and easy access to information about generic medicines (eg, via the Internet) has become more common in recent years. Further, registration requirements of generic medicines by regulatory drug authorities (eg, bioequivalence and its requirement criteria) are different to those of the 1970s and 1980s. Thus, including the recent literature makes this review more contemporary and more relevant to today's practice. A second limitation is that studies not published in English were excluded from this review. A third limitation is that the literature search was not done using all available databases. As a result, it is possible that some important studies might have been missed. However, the review was not intended to be exhaustive, but merely an attempt to examine the general perceptions of consumers regarding generic medicines.

\section{Conclusion}

The results of this review show that medicine consumers and patients tend to prefer original brand medicines over generic medicines. Moreover, a large body of literature has reported misconceptions and negative perceptions regarding generic medicines among patients and medicine consumers. However, although reported in almost all countries, the percentage of consumers with such misconceptions can vary widely from one country to another. Studies focusing on specific populations, eg, patients with epilepsy, psychosis, or a renal transplant, reported more negative perceptions and more resistance to use of generic medicines. The type of medical condition and its seriousness or severity, recommendation by health care professionals, price difference (ie, cost saving), previous experience of generic medicines, and knowledge/information about generic medicines were considered to be important factors affecting a patient's decision to use a generic medicine or brand medicine. There is strong evidence in the literature that health care professionals, including physicians and pharmacists, play a key role in promotion of generic medicines, patients' acceptance of their use, and generic substitution. Thus, in addition to activities designed to educate patients about generic medicines, health care professionals need to play a more active role by educating patients and recommending generic medicines more often.

\section{Disclosure}

The authors report no conflicts of interest in this work.

\section{References}

1. Dunne S, Shannon B, Dunne C, Cullen W. A review of the differences and similarities between generic drugs and their originator counterparts, including economic benefits associated with usage of generic medicines, using Ireland as a case study. BMC Pharmacol Toxicol. 2013;14(1):1.

2. World Health Organization. Glossary of Globalization, Trade and Health Terms. 2012. Available from: http://www.who.int/trade/glossary/ story034/en/index.html. Accessed January 30, 2014.

3. The US Food and Drug Administration. FDA Center for Drug Evaluation and Research. Office of Generic Drugs. Facts about generic drugs. 2012. Available from: http://www.fda.gov/Drugs/ResourcesForYou/ Consumers/BuyingUsingMedicineSafely/UnderstandingGenericDrugs/ ucm 167991.htm. Accessed January 30, 2014.

4. European Generic Medicines Association. EGA fact sheet on generic medicines: assured quality, safety and efficacy of generic medicines. Available from: http://www.egagenerics.com/images/factsheet/ EGA_factsheet_01.pdf. Accessed January 30, 2014.

5. Galgatte UC, Jamdade VR, Aute PP, Chaudhari PD. Study on requirements of bioequivalence for registration of pharmaceutical products in USA, Europe and Canada. Saudi Pharm J. Epub 2013 May 31.

6. Shafie AA, Hassali MA. Price comparison between innovator and generic medicines sold by community pharmacies in the state of Penang, Malaysia. Journal of Generic Medicines. 2008;6(1):35-42.

7. Matin Y. SCRIP's Complete Guide to the World Generic Drugs Market Richmond, UK: PJB Publications Ltd; 1999.

8. European Generic Medicines Association. EGA fact sheet on generic medicines: frequently asked questions (FAQs). http://www.egagenerics. com/images/factsheet/EGA_factsheet_06.pdf. Accessed January 30, 2014.

9. Simoens S, Coster SD. Sustaining generic medicines markets in Europe. Research Centre for Pharmaceutical Care and Pharmaco-economics, Katholieke Universiteit Leuven 2006. Available from: http://212.85.101.126/images/publikacje/7_pl.pdf. Accessed January 30, 2014.

10. Sheppard A. Generic medicines: essential contributors to the long-term health of society. IMS Health. Available from: http://www.imshealth. com/imshealth/Global/Content/Document/Market_Measurement_TL/ Generic_Medicines_GA.pdf. Accessed January 30, 2014.

11. Alrasheedy AA, Hassali MA, Aljadhey H, Ibrahim MIM, Al-Tamimi SK. Is there a need for a formulary of clinically interchangeable medicines to guide generic substitution in Saudi Arabia? J Young Pharm. 2013;5(2):73-75.

12. Godman B, Malmström R, Bennie M, et al. Prescribing restrictions a necessary strategy among some European countries to enhance future prescribing efficiency? Rev Health Care. 2012;3(1):5-16. 
13. Godman B, Shrank W, Wettermark B, et al. Use of generics - a critical cost containment measure for all health care professionals in Europe? Pharmaceuticals. 2010;3(8):2470-2494.

14. Godman B, Wettermark B, Bishop I, Burkhardt T, Fürst J, Garuoliene K. European payer initiatives to reduce prescribing costs through use of generics. GaBi J. 2012;1(1):22-27.

15. Ministry of Health Labour and Welfare of Japan. Policy report: promotion of the use of generic drugs. 2012. Available from: http:/ www.mhlw.go.jp/english/policy_report/2012/09/120921.html. Accessed January 30, 2014.

16. Sermet C, Andrieu V, Godman B, Van Ganse E, Haycox A, Reynier J-P. Ongoing pharmaceutical reforms in France. Appl Health Econ Health Policy. 2010;8(1):7-24.

17. Simoens S, De Coster S. Sustaining generic medicines markets in Europe. Journal of Generic Medicines. 2006;3(4):257-268.

18. Dylst P, Vulto A, Simoens S. Demand-side policies to encourage the use of generic medicines: an overview. Expert Rev Pharmacoecon Outcomes Res. 2013;13(1):59-72.

19. Moher D, Liberati A, Tetzlaff J, Altman DG, The PG. Preferred Reporting Items for Systematic Reviews and Meta-Analyses: the PRISMA statement. PLoS Med. 2009;6(7):e1000097.

20. Ganther J, Kreling D. Consumer perceptions of risk and required cost savings for generic prescription drugs. J Am Pharm Assoc (Wash). 2000;40(3):378-383.

21. Sansgiry SS, Bhosle M, Pope N. Consumer perceptions regarding generic drug substitution: an exploratory study. J Pharm Mark Manage. 2005;17(1):77-91.

22. Iosifescu A, Halm EA, McGinn T, Siu AL, Federman AD. Beliefs about generic drugs among elderly adults in hospital-based primary care practices. Patient Educ Couns. 2008;73(2):377-383.

23. Shrank WH, Cox ER, Fischer MA, Mehta J, Choudhry NK. Patients' perceptions of generic medications. Health Aff (Millwood). 2009;28(2):546-556.

24. Shrank WH, Cadarette SM, Cox E, et al. Is there a relationship between patient beliefs or communication about generic drugs and medication utilization? Med Care. 2009;47(3):319-325.

25. Papsdorf TB, Ablah E, Ram S, Sadler T, Liow K. Patient perception of generic antiepileptic drugs in the Midwestern United States. Epilepsy Behav. 2009;14(1):150-153.

26. Keenum AJ, DeVoe JE, Chisolm DJ, Wallace LS. Generic medications for you, but brand-name medications for me. Res Social Adm Pharm. 2012;8(6):574-578.

27. Sewell K, Andreae S, Luke E, Safford MM. Perceptions of and barriers to use of generic medications in a rural African American population, Alabama, 2011. Prev Chronic Dis. 2012;9:E142.

28. Kohli E, Buller A. Factors influencing consumer purchasing patterns of generic versus brand name over-the-counter drugs. South Med J. 2013;106(2):155-160.

29. Pereira JA, Holbrook AM, Dolovich L, et al. Are brand-name and generic warfarin interchangeable? A survey of Ontario patients and physicians. Can J Clin Pharmacol. 2005;12(3):e229-e239.

30. Hassali MA, Kong D, Stewart K. Generic medicines: perceptions of consumers in Melbourne, Australia. Int J Pharm Pract. 2005;13(4): 257-264.

31. Bulsara C, McKenzie A, Sanfilippo F, Holman CAJ, Emery JE. 'Not the full Monty': a qualitative study of seniors' perceptions of generic medicines in Western Australia. Aust J Prim Health. 2010;16(3): 240-245.

32. Ibrahim R, McKinnon RA, Ngo SN. Knowledge and perceptions of community patients about generic medicines. Journal of Pharmacy Practice and Research. 2012;42(4):283-286.

33. Ngo SN, Stupans I, McKinnon RA. Generic substitution in the treatment of epilepsy: patient attitudes and perceptions. Epilepsy Behav. 2013;26(1):64-66.

34. Babar ZU, Stewart J, Reddy S, et al. An evaluation of consumers' knowledge, perceptions and attitudes regarding generic medicines in Auckland. Pharm World Sci. 2010;32(4):440-448.
35. Al-Gedadi NA, Hassali MA, Shafie AA. A pilot survey on perceptions and knowledge of generic medicines among consumers in Penang, Malaysia. Pharm Pract (Internet). 2008;6(2):93-97.

36. Thomas R, Vitry A. Consumers' perception of generic medicines in community pharmacies in Malaysia. South Med Rev. 2009;2(2):20-23.

37. Abzakh AA, Ling KC, Alkilani K. The impact of perceived risks on the consumer resistance towards generic drugs in the Malaysia pharmaceutical industry. International Journal of Business and Management. 2013;8(3):42-50.

38. Hoshi S, Kimura H. Questionnaire on the awareness of generic drugs among outpatients and medical staff. Drug Discov Ther. 2008;2(3):194-199.

39. Kobayashi E, Karigome H, Sakurada T, Satoh N, Ueda S. Patients' attitudes towards generic drug substitution in Japan. Health Policy. 2011;99(1):60-65.

40. Ahire K, Shukla M, Gattani M, Singh V, Singh M. A survey-based study in current scenario of generic and branded medicines. Int J Pharm Pharm Sci. 2013;5(3).

41. Sharrad AK, Hassali MA. Consumer perception on generic medicines in Basrah, Iraq: preliminary findings from a qualitative study. Res Social Adm Pharm. 2011;7(1):108-112.

42. Toklu HZ, Dülger GA, Hidiroğlu S, et al. Knowledge and attitudes of the pharmacists, prescribers and patients towards generic drug use in Istanbul, Turkey. Pharm Pract (Granada). 2012;25(35):36-45.

43. El-Dahiyat F, Kayyali R. Evaluating patients' perceptions regarding generic medicines in Jordan. Journal of Pharmaceutical Policy and Practice. 2013;6(1):3.

44. Al Ameri M, Mohamed W, Makramalla E, Shalhoub B, Tucker A, Johnston A. Renal patients' views on generic prescribing and substitution: example from the United Arab Emirates. East Mediterr Health J. 2013;19(4):373-381.

45. Albarraq A. Consumers' perceptions on generic medicines in Taif city, Saudi Arabia. Saudi Journal for Health Sciences. 2013;2(1):18-22.

46. Heikkilä R, Mäntyselkä P, Hartikainen-Herranen K, Ahonen R. Customers' and physicians' opinions of and experiences with generic substitution during the first year in Finland. Health Policy. 2007;82(3):366-374.

47. Halme M, Linden K, Kääriä K. Patients' preferences for generic and branded over-the-counter medicines. Patient. 2009;2(4):243-255.

48. Heikkilä R, Mäntyselkä P, Ahonen R. Do people regard cheaper medicines effective? Population survey on public opinion of generic substitution in Finland. Pharmacoepidemiol Drug Saf. 2011;20(2):185-191.

49. Heikkilä R, Mäntyselkä P, Ahonen R. Price, familiarity, and availability determine the choice of drug - a population-based survey five years after generic substitution was introduced in Finland. BMC Pharmacol Toxicol. 2011;11(1):20.

50. Heikkilä R, Mäntyselkä P, Ahonen R. Why people refuse generic substitution: a population survey of public opinion on generic substitution in Finland. Drugs and Therapy Perspectives. 2012;28(8):24-26.

51. Rozano Suplet M, Gómez Suárez M, Díaz Martín AM. Customer perceptions of perceived risk in generic drugs: the Spanish market. Innovar. 2009;19(34):53-64.

52. Sicras-Mainar A, Navarro-Artieda R. Physicians' and patients' opinions on the use of generic drugs. J Pharmacol Pharmacother. 2012;3(3):268-270.

53. Figueiras MJ, Marcelino D, Cortes MA. People's views on the level of agreement of generic medicines for different illnesses. Pharm World Sci. 2008;30(5):590-594.

54. Figueiras MJ, Alves NC, Marcelino D, Cortes MA, Weinman J, Horne R. Assessing lay beliefs about generic medicines: development of the generic medicines scale. Psychol Health Med. 2009;14(3):311-321.

55. Figueiras MJ, Cortes MA, Marcelino D, Weinman J. Lay views about medicines: the influence of the illness label for the use of generic versus brand. Psychol Health. 2010;25(9):1121-1128.

56. Figueiras M, Marcelino DS, Claudino A, Cortes MA, Maroco J, Weinman J. Patients' illness schemata of hypertension: the role of beliefs for the choice of treatment. Psychol Health. 2010;25(4):507-517. 
57. Quintal C, Mendes P. Underuse of generic medicines in Portugal: an empirical study on the perceptions and attitudes of patients and pharmacists. Health Policy. 2012;104(1):61-68.

58. Palagyi M, Lassanova M. Patients' attitudes towards experience with use of generics in Slovakia, performance of generic substitution. Bratisl Lek Listy. 2008;109(7):324-328.

59. Frisk P, Rydberg T, Carlsten A, Ekedahl A. Patients' experiences with generic substitution: a Swedish pharmacy survey. J Pharm Health Serv Res. 2011;2(1):9-15.

60. Kjoenniksen I, Lindbaek M, Granas AG. Patients' attitudes towards and experiences of generic drug substitution in Norway. Pharm World Sci. 2006;28(5):284-289.

61. Toverud E-L, Røise AK, Hogstad G, Wabø I. Norwegian patients on generic antihypertensive drugs: a qualitative study of their own experiences. Eur J Clin Pharmacol. 2011;67(1):33-38.

62. Lebanova H, Manolov D, Getov I. Patients' attitudes about generics Bulgarian perspective. Marmara Pharm J. 2012;16:36-40.

63. Himmel W, Simmenroth-Nayda A, Niebling W, et al. What do primary care patients think about generic drugs? Int J Clin Pharmacol Ther. 2005;43(10):472-479.

64. Hensler K, Uhlmann C, Porschen T, Benecke R, Rösche J. Generic substitution of antiepileptic drugs - a survey of patients' perspectives in Germany and other German-speaking countries. Epilepsy Behav. 2013;27(1):135-139.

65. Al Ameri MN, Whittaker C, Tucker A, Yaqoob M, Johnston A. A survey to determine the views of renal transplant patients on generic substitution in the UK. Transpl Int. 2011;24(8):770-779.
66. Rathe J, Larsen P, Andersen M, et al. Associations between generic substitution and patients' attitudes, beliefs and experiences. Eur J Clin Pharmacol. 2013;69(10):1827-1836.

67. Roman B. Patients' attitudes towards generic substitution of oral atypical antipsychotics. CNS Drugs. 2009;23(8):693-701.

68. Gill L, Helkkula A, Cobelli N, White L. How do customers and pharmacists experience generic substitution? International Journal of Pharmaceutical and Healthcare Marketing. 2010;4(4):375-395.

69. Denoth A, Pinget C, Wasserfallen J-B. Citizens' preferences for brand name drugs for treating acute and chronic conditions. Appl Health Econ Health Policy. 2011;9(2):81-87.

70. Gossell-Williams M, Harriott K. Generic substitution in Jamaica: challenges to improving effectiveness. WHO Drug Information. 2007;21(4):294-299.

71. Patel A, Gauld R, Norris P, Rades T. "This body does not want free medicines": South African consumer perceptions of drug quality. Health Policy Plan. 2010;25(1):61-69.

72. Bertoldi AD, Barros AJ, Hallal PC. [Generic drugs in Brazil: known by many, used by few]. Cad Saude Publica. 2005;21(6):1808-1815. Portuguese.

73. Hassali MA, Shafie AA, Jamshed S, Ibrahim MI, Awaisu A. Consumers' views on generic medicines: a review of the literature. Int $J$ Pharm Pract. 2009;17(2):79-88.

74. Gaither CA, Kirking DM, Ascione FJ, Welage LS. Consumers' views on generic medications. J Am Pharm Assoc. 2001;41(5):729-736.
Patient Intelligence

\section{Publish your work in this journal}

Patient Intelligence is an international, peer-reviewed, open access journal that characterizes and measures the central role of patient behavior and intention in optimizing healthcare management in all areas of disease and complaint types. An improved understanding of patient intelligence coupled with predictive analysis helps an organization contribute more effectively to achieving better outcomes.

\section{Dovepress}

The journal is characterized by the rapid reporting of reviews, original research, methodologies, analytics, modeling, clinical studies and patient surveys across all disease areas. The manuscript management system is completely online and includes a very quick and fair peer-review system. Visit http://www.dovepress.com/ testimonials.php to read real quotes from published authors. 